\title{
CYCLIC BEHAVIOR AND PORE PRESSURE GENERATION IN SANDS WITH LAPONITE, A SUPER-PLASTIC NANOPARTICLE
}

\author{
Felipe Ochoa-Cornejo ${ }^{\mathrm{a}}$, Antonio Bobet ${ }^{\mathrm{b}}$, Cliff T Johnston $^{\mathrm{c}}$, \\ Marika Santagata $^{\mathrm{d}^{*}}$, Joseph V. Sinfield ${ }^{\mathrm{e}}$
}

\begin{abstract}
The paper examines the effect of the presence of small percentages (1-5\%) by dry mass of the sand of laponite - a synthetic nanoclay with plasticity index exceeding $1000 \%$ - on the cyclic response of sand with $D_{r}$ in the $15 \%-25 \%$ range. The work is based on cyclic triaxial tests performed on specimens prepared pluviating sand and laponite under dry conditions and then permeated with water. 1\% laponite impacts all stages of the cyclic tests, from the response during the first loading cycle to liquefaction, increasing the cyclic resistance. Further benefits are observed with a longer pre-shear aging period or higher dosages (3-5\%) of laponite.

The observed behavior is associated with reduced mobility of the sand particles during cyclic loading, which can be ascribed to two mechanisms: (1) bonding/bridging at the particle contacts due to the charged laponite fines which are attracted to the sand grains; and (2) formation of a pore fluid with solid like properties. The first appears to control the behavior with 1\% laponite, while it is proposed that the second is responsible for the response with higher dosages of laponite.

The results presented provide new insight into the effects of high plastic fines on the cyclic response of sands, the "extreme" effects of the plasticity of the fines, and are significant in light of the possible use of laponite for liquefaction mitigation, an idea first put forth by the authors.

\footnotetext{
* Corresponding author

${ }^{a}$ Assistant Professor -Civil Engineering Department, University of Chile, Beauchef 850, Santiago of Chile, Chile; +56229780914; fochoa@ing.uchile.cl

${ }^{\mathrm{b}}$ Professor - School of Civil Engineering, Purdue University, 550 Stadium Mall Dr., West Lafayette, IN 47907; (765) 494-5033; bobet@purdue.edu ${ }^{\mathrm{c}}$ Professor - Department of Agronomy, Purdue University, 915 W State Street, West Lafayette, IN 47907; (765) 496-1716; cliffjohnston@purdue.edu

${ }^{\mathrm{d}}$ Associate Professor - School of Civil Engineering, Purdue University, 550 Stadium Mall Dr., West Lafayette, IN 47907; (765) 494-0697; FAX: (765) 494-0395; mks@purdue.edu

${ }^{\mathrm{e}}$ Associate Professor - School of Civil Engineering, Purdue University, 550 Stadium Mall Dr., West Lafayette, IN 47907; (765) 496-2742; jvs@purdue.edu
} 


\section{Introduction}

Pore pressures are fundamental to understand soil behavior, as in saturated soils they define effective stresses, which ultimately control the stress-strain-strength behavior of soils. In the context of earthquake geotechnical engineering, of particular significance is the generation of excess pore pressure that occurs in granular deposits due to ground shaking, as the accumulation of excess pore pressure and the related decrease in effective stresses associated with this process can eventually lead to liquefaction, a phenomenon characterized by large deformations and in some cases catastrophic failure of structures on loose to medium granular deposits (e.g. [1-4])

Cyclic behavior and pore pressure generation in granular soil deposits have been the object of extensive research, with efforts focused on the response of clean sands (e.g. [5-7]). However, natural sand deposits present different amounts of fines and levels of cementation, encouraging the study of the effect of these variables on the cyclic behavior of sands (e.g. [811]).

Studies on the impact of non-plastic fines on the cyclic response and pore pressure development of sands present a wide variety of results (e.g. [12-16]). In contrast, it is fairly accepted that the presence of plastic fines (e.g. [2,17-20]) and cementation (e.g. [11,21]) increase the cyclic resistance of sands.

Recently, El Mohtar et al. [22,23] examined the effect of small percentages (3-5\%) of bentonite on the cyclic resistance of sands. These clay percentages are at the low end of those examined by other researchers, and smaller than the threshold values that are thought to impact liquefaction resistance (e.g., in Youd et al. [24], the curve for fines content less than 5\% is referred to as the "clean sand base curve"). The work by El Mohtar et al. [22,23], which was aimed at developing a method for improving the liquefaction resistance of granular soils, highlighted how amounts of bentonite as small as $3 \%$ by dry mass of the sand lead to an increase in the cyclic resistance of sand of over an order of magnitude. Moreover, the cyclic resistance continues to improve with continuous aging of the soil.

The work presented in this paper builds on this previous research and examines the effect of the presence of small percentages of laponite on the response of sands to cyclic shear. Laponite is a synthetic clay with particle diameter approximately ten times smaller than bentonite, and plasticity index of $1,100 \%$, significantly greater than that of bentonite, justifying its designation as a "super-plastic" clay. 
Cyclic triaxial tests are conducted on specimens prepared mixing sand and 1\% laponite (by dry mass of the sand) under dry conditions and subsequently saturated with water. Additional tests are conducted with dosages of 3\% and 5\% laponite. The response of these specimens is evaluated by comparison with clean sand specimens tested under similar conditions (skeleton relative density and cyclic stress ratio), with specific focus on the analysis of the excess pore pressure response. The paper carefully examines the generation of pore pressure during the various stages of cyclic loading, starting from the first loading cycle to the triggering of large strains, to the initiation of liquefaction.

As the presence of as little as $1 \%$ of laponite (by dry mass of the sand) is found to impact the cyclic response of the granular medium significantly, the tests on sand-laponite mixtures provide the means to examine the "extreme" effects of the plasticity of the fines.

Moreover, analysis of the results for different amounts of laponite and comparison to the existing database for sand-bentonite specimens [22,23] provide insight into the relative impact of the testing parameters (percentage and plasticity of the fines, and time). They also highlight how, depending on the nature and the fines content, different mechanisms may be responsible for the observed increase in cyclic strength.

Finally, the cyclic behavior of sand-laponite mixtures is also relevant to the potential use of laponite as an alternative to bentonite for treating liquefiable soils. This idea was first put forth by the authors" research team at Purdue University [25-27]. While bentonite is natural and safe, its application in the field presents some challenges related to (1) the chemical treatment with sodium pyro-phosphate required to control the short-term viscosity of bentonite dispersions to allow permeation in a porous medium [27]; (2) the inherent variability of this natural material, which can lead to inconsistent results; and (3) difficulties in permeating finer deposits. Laponite potentially overcomes these challenges due to its smaller size when fully dispersed, its consistent properties, and the delayed gelation properties of laponite dispersions. In this context, this research provides insight into the amount of laponite that might be necessary to deliver in a porous medium for improving its liquefaction resistance and the changes in engineering properties that might be anticipated. 


\section{Materials, Equipment, and Experimental Procedures}

\subsection{Materials}

As discussed in more detail below, the experimental program included undrained cyclic triaxial testing on cylindrical specimens prepared with clean Ottawa sand (C778) and mixtures of Ottawa sand and laponite.

Ottawa sand is a clean uniform $\left(\mathrm{C}_{\mathrm{u}}=1.48\right)$ silica sand with particle size distribution in the fine-to-medium range (100 to $600 \mu \mathrm{m}$ ), and less than 1\% fines. Ottawa sand particles have a rounded to sub-rounded shape, soft gray color and specific gravity $\left(\mathrm{G}_{\mathrm{s}}\right)$ of 2.65. The maximum and minimum void ratios are $\mathrm{e}_{\max }=0.480$ and $\mathrm{e}_{\min }=0.783$ [28].

Laponite, $\mathrm{Na}_{+0.7}\left[\left(\mathrm{Si}_{8} \mathrm{Mg}_{5.5} \mathrm{Li}_{0.3}\right) \mathrm{O}_{20}(\mathrm{OH})_{4}\right]_{-0.7}$, is a synthetic nanoclay similar to natural hectorite, which is used as a rheology modifier in a range of applications (e.g. cosmetics, inks, paints, surface coatings, glazes). It is a 2:1 clay formed by a magnesium octahedral sheet sandwiched between two silica tetrahedral sheets (Figure 1a). Isomorphic substitution of magnesium by lithium atoms generates negative charges on both faces, which are counterbalanced by interlayer cations, generally sodium. The rims have weaker $\mathrm{pH}$ dependent positive charge. Single laponite particles have a disk-like shape approximately $25 \mathrm{~nm}$ in diameter and $1 \mathrm{~nm}$ thickness (Figure $1 \mathrm{~b}$ ) and specific gravity of 2.57; bentonite particles also have a fundamental thickness of $1 \mathrm{~nm}$ but the diameter is much greater than laponite (200 to $1000 \mathrm{~nm}$ ), In dry form, laponite crystals form silt size stacks by sharing the interlayer sodium ions. When dispersed in water, laponite hydrates and swells, forming a clear, primarily monodisperse suspension, with behavior controlled by electrical interactions. Depending on the experimental conditions (clay concentration, $\mathrm{pH}$, ionic strength) repulsive or attractive forces control the structure and the response of the dispersion (e.g. [29-32]).

As a result of the small particle size and its affinity for water, laponite has a plasticity index (PI) of approximately $1,100 \%$ [25]. This PI is significantly greater than that of natural clays (e.g. for bentonite PI 350, [23]).

Laponite dispersions have rheological properties - early Newtonian behavior and delayed gelation process (e.g. [29,32,33]) - that are very attractive from the standpoint of delivering this nano-clay into the subsurface. This aspect of behavior is not addressed in this paper, as the focus is on the cyclic response of specimens prepared mixing sand and laponite under dry conditions, and subsequently permeated with water. 
Laponite is manufactured and commercialized by BYK Additives and Instruments (previously Rockwood Additives Inc.) in different grades. The general purpose grade, laponite $\mathrm{RD}$, referred to as laponite, was used in this work. Laponite RD is the material most extensively documented in the literature.

\subsection{Specimen Preparation and Testing Procedures}

Two triaxial apparatuses were used to perform the cyclic tests presented in this paper: the CKC system from Soil Testing Equipment (San Francisco, CA) and the STX-050 system from GCTS (Tempe, AZ).

Cyclic tests were conducted on clean sand and sand-laponite specimens prepared by dry pluviation. The composite material was prepared by placing sand and laponite in the desired proportions (e.g. 1\% of laponite by-dry-mass of sand) in a sealed plastic container. Afterward, the container with the mixed material was manually shaken for 20 minutes. A valve on the container, connecting to a copper pipe of $30 \mathrm{~cm}$ in length and $0.50 \mathrm{~cm}$ in diameter, was used to air-pluviate the mixture inside the triaxial split mold. A similar container was used for clean sand specimens. Air pluviation procedures were calibrated to achieve skeleton relative densities $\left(\mathrm{D}_{\text {rsk }}\right)$ around $20 \%$ for both types of specimens. The skeleton relative density is calculated based on the skeleton void ratio (which considers that only the sand contributes to the solid phase) and the limiting void ratios $\left(\mathrm{e}_{\max }\right.$ and $\left.\mathrm{e}_{\min }\right)$ of the clean sand.

The dry pluviation procedure outlined above was selected based on previous experience $[22,23]$ with sand-bentonite (3 and 5\%) mixtures, which showed that it was effective in producing homogeneous specimens with minimal spatial variability in bentonite content (within $0.25 \%$ of the targeted bentonite percentage).

Following setup, the specimens were first flushed with carbon dioxide $\left(\mathrm{CO}_{2}\right)$ and deionized de-aired water under an effective stress of 25-50 kPa, and then backpressure saturated to 200-300 $\mathrm{kPa}$ to reach a B-value of at least 0.95. All specimens were then isotropically consolidated to an effective stress of $100 \mathrm{kPa}$. Irrespective of the presence of laponite, the consolidation process was found to occur in less than 10 seconds. Clean sand specimens were sheared after one hour of secondary consolidation, or aging, while for the majority of the sandlaponite specimens, the aging stage was extended to 72 hours (with the effect of the aging duration examined in a select number of tests). The aging period was based on results of 
rheological tests, which showed that at 72 hours the rheological properties of the laponite pore fluid expected to develop in the pore space were similar to those of the bentonite dispersions examined in $[22,23]$.

Cyclic loading was conducted at the end of the aging phase under undrained conditions with a vertical loading frequency of $1 \mathrm{~Hz}$. Applied cyclic stress ratios (CSR) ranged between 0.1 and 0.15 for clean sand and between 0.12 and 0.25 for sand with laponite. Test information was recorded with a rate of 33 samples per cycle.

\subsection{Testing Program}

The testing program included 21 tests, L1 to L21, on dry-mixed sand-laponite specimens. Table 1 summarizes the testing conditions examined, including type and percentage of fines, skeleton relative density at end of consolidation, duration of the pre-shear aging stage, and the cyclic stress ratio (CSR) applied during the undrained shear stage. Table 1 also presents a series of parameters that are used to characterize the cyclic response of the specimens.

Also included in Table 1 are data for clean sand specimens obtained as part of this research project and during a previous research effort documented in [22,23]. These data (tests CS1 CS7) pertain to specimens prepared at similar values of the skeleton relative density.

\section{Cyclic Triaxial Tests Results}

\subsection{Undrained Cyclic Resistance}

Figure 2 and Figure 3 show the response of clean sand (Test CS3 with $\mathrm{D}_{\text {rsk }}=18 \%$ and $\mathrm{CSR}=0.096$ ) and sand-laponite specimens (Test L2 with $\mathrm{D}_{\mathrm{rsk}}=15 \%$ and $\mathrm{CSR}=0.137$ ) subjected to cyclic loading. The figures report the applied deviatoric stress (Figures 2a and 3a), the axial strain (Figures $2 \mathrm{~b}$ and $3 \mathrm{~b}$ ), and the excess pore pressure ratio (Figures $2 \mathrm{c}$ and $3 \mathrm{c}$ ) versus the number of cycles $(\mathrm{N})$, as well as the stress paths in the MIT $\mathrm{p}^{\mathrm{ee}}-\mathrm{q}$ space (Figures $2 \mathrm{~d}$ and $3 \mathrm{~d}$ ).

It is seen that $100 \%$ of excess pore pressure is developed in both specimens, causing the soil to reach a state of zero effective stress, and triggering large axial deformations. Despite the lower skeleton relative density and higher CSR applied, the sand-laponite specimen shows a significant increase in the number of cycles to reach $100 \%$ of excess pore pressure compared to the clean sand (from 125 to over 500 cycles). As shown below, under a $\mathrm{CSR}=0.137$ the clean sand specimen would be able to resist only 1 to 2 loading cycles. The specimen deformations, 
depicted by the axial strain plots in Figures $2 \mathrm{~b}$ and $3 \mathrm{~b}$ indicate small strains, almost negligible, for most of the cycles applied. This condition is observed until very close to the point of $100 \%$ of excess pore pressure development (or liquefaction) when a rapid and significant increase in the measured axial strains is observed.

Despite the differences in the number of cycles to liquefaction $\left(\mathrm{N}_{\mathrm{Liq}}\right)$, the development of excess pore pressure shows a similar trend in the two specimens: a first initial rapid increase, followed by a "plateau," where the rate of excess pore pressure generation is approximately constant, and a final rapid acceleration in excess pore pressure generation, reaching full development of excess pore pressure after a few cycles of loading.

Comparison of Figures $2 \mathrm{c}$ and $3 \mathrm{c}$ shows that the presence of $1 \%$ laponite in the sand matrix affects all the stages of excess pore pressure generation of the granular material, leading to an increase in the cyclic resistance of the sand. This observation is discussed in more detail below. The effective stress paths of the specimens during testing shown in Figures $2 d$ and $3 d$, reflect the increase in pore pressure with cyclic loading. As the number of cycles increases, the effective stress paths move toward the left, eventually intersecting the failure envelope of the material. At this point, the deviatoric shear stress is bound by the critical state line, and it can no longer be sustained by the specimen, eventually decreasing, as shown in Figures 2a and 3a.

The results from all cyclic triaxial tests performed on clean sand and sand with $1 \%$ laponite specimens are summarized in Figure 4. They are plotted in terms of the cyclic stress ratio (CSR) versus the number of cycles to liquefaction (on a logarithmic scale). As summarized in Table 1, the majority of specimens were prepared with end of consolidation values of the skeleton relative density, $\mathrm{Dr}_{\mathrm{sk}}$, between $15 \%$ and $25 \%$. The symbol with the arrow in Figure 4 indicates the number of cycles at which the test was terminated after the specimen reached a plateau of constant pore pressure generation, without reaching liquefaction.

Figure 4 shows that, as expected, for both clean sand and sand-laponite specimens, the number of cycles to liquefaction $\left(\mathrm{N}_{\mathrm{Liq}}\right)$ increases as the level of applied cyclic shear (CSR) decreases. The plot shows the significant increase in the cyclic resistance due to the presence of $1 \%$ laponite in the matrix of sand. At the same CSR, the number of cycles needed to cause liquefaction of the sand-laponite specimens is over one order of magnitude greater compared to clean sand. Note that, while falling on two distinct bands, the data show some scatter around the trend lines. This is not uncommon (e.g. [34]) especially for low values of CSR. 
As stated above, and summarized in Table 1, the clean sand and sand-laponite specimens were tested after different durations of the post-consolidation aging period ( 1 hour and 72 hours, respectively). Aging is known to lead to an increase in the liquefaction resistance of sands (e.g. [35-37]) and it is important to assess to what degree the increase in cyclic resistance observed with the addition of $1 \%$ laponite can be ascribed to the increased duration in aging. Based on the analysis of extensive laboratory and field data, Hayati and Andrus [37] propose two relationships for estimating $K_{D R}$, the factor used to correct the cyclic resistance for the effects of age, cementation and stress history.

The first relationship is based on the age of the sand, and utilizes an average reference age of two days for the reconstituted specimens. Given that the aging times considered in this study fall below or very close to this reference time, use of this relationship does not appear appropriate. The second relation linearly relates the increase in cyclic resistance to the increase in shear wave velocity observed over the same period. This relation can be used, given the availability [38] of shear wave velocity data collected as a function of time in resonant column tests performed on the same soils examined in this paper. For clean sand, these data show no detectable changes in the measured shear wave velocity between 1 and 72 hours, indicating that the difference in aging duration likely plays a negligible role in determining the relative position of the curves reported in Figure 4.

The number of cycles to liquefaction $\left(\mathrm{N}_{\mathrm{Liq}}\right)$ reported in Table 1 and Figure 4 was identified for each test in correspondence to the excess pore pressure reaching a value equal to the initial effective confinement, i.e., $100 \%$ of excess pore pressure relative to the initial effective stress, $\sigma_{0}^{e e}$. This liquefaction criterion is known as „Initial Liquefaction ${ }^{\text {ee }}$ [39]. Another criterion employed in the literature identifies liquefaction based on the development of a certain level of axial strain [2], since, as shown in Figures $2 \mathrm{~b}$ and $3 \mathrm{~b}, 100 \%$ of excess pore pressure triggers significant axial deformation of the specimens. In particular, the development of $5 \%$ double amplitude (D.A.) axial strain has been widely used in the literature to identify the number of cycles causing liquefaction.

Figure 5 compares the number of cycles to liquefaction $\left(\mathrm{N}_{\mathrm{Liq}}\right)$ determined using the initial liquefaction and the number of cycles corresponding to a peak-to-peak axial strain of 5\%. It is observed that, as already reported by other authors (e.g. [40]), the two criteria produce consistent results. 


\subsection{Pore Pressure Generation}

The excess pore pressure generated during cyclic shearing has been widely recognized as a key parameter to understand the cyclic resistance of saturated sands [3,8,41]. Insight into the role

played by laponite can be gained by looking more closely at this aspect of behavior. Figure $6 \mathrm{a}$ shows the curves of excess pore pressure normalized by the initial effective confining stress $\left(\sigma_{0}^{e e}\right)$ versus the number of cycles for the two tests examined in Figures 2 and 3. Similar data for sandlaponite specimens sheared at different values of CSR are presented in Figure 6b.

Figure $6 \mathrm{a}$ shows that, as described above, the presence of $1 \%$ laponite extends the number of cycles to reach liquefaction, increasing the cyclic resistance relative to clean sands, despite the higher values of the CSR. For all specimens, independent of the presence of laponite and the CSR applied, the evolution of the excess pore pressure follows the pattern described previously. There is an initial rapid increase in the excess pore pressure, a "plateau" where the excess pore pressure increases linearly, and a final sharp acceleration of the excess pore pressure, with the specimen reaching liquefaction $\left(\Delta \mathrm{u} / \sigma_{0}^{\mathrm{ee}}=100 \%\right)$ after a few additional cycles of loading. Figure $6 \mathrm{~b}$ illustrates the effect of increasing CSR on the sand-laponite specimens. As expected, the number of cycles to liquefaction reduces with increasing CSR. This seems to be associated with a larger rate of increase of the pore pressures in the "plateau" regime.

Given that the number of cycles to liquefaction depends on the CSR, the data in Figure 6 can be normalized plotting the excess pore pressure ratio $\left(\Delta \mathrm{u} / \sigma_{0}^{\mathrm{ee}}\right)$ as a function of the normalized number of cycles to liquefaction $\left(\mathrm{N} / \mathrm{N}_{\mathrm{Liq}}\right)$. Moreover, to separate the recoverable component that is associated with each loading cycle and the mean excess pore pressure accumulated from one cycle to the next, the residual excess pore pressure ratio, $r_{u}$, which is eventually responsible for liquefaction, is plotted on the ordinate.

Curves of $r_{u}$ versus $N / N_{L i q}$ for tests on the clean sand with CSR ranging between 0.089 and 0.118 are presented in Figure 7a. From Figure 4 it is seen that over this range of values of the CSR, the number of cycles to liquefaction increases from about 20 to over 200. This same normalized representation is used in Figure $7 \mathrm{~b}$ to report data obtained from sand-laponite specimens, sheared with CSR ranging between 0.137 and 0.239 . This range of CSR values corresponds to a broad range of cycles to liquefaction (from less than 5 to over 500). Both figures include the band of excess pore pressure generation curves proposed by Lee and Albaisa 
[42] and complemented by De Alba et al. [1], based on an extensive testing program conducted on Monterrey and Sacramento sands. In these works, the relative density varied between $30 \%$ and $90 \%$, and the CSR ranged between 0.10 and 0.28 . In general, the upper boundary corresponds to sands sheared at lower CSR values (and/or higher relative density). The lower boundary is, instead, associated with the behavior of specimens sheared with higher CSR.

Figure 7a shows that the behavior of clean Ottawa sand falls within the range established for clean sands by Lee an Albaisa [42] and De Alba et al. [1]. As previously shown in these studies, as the CSR increases, the curves shift downwards, approaching the lower bound of the envelope. This observation indicates that, with increasing CSR, the same loss in effective stress occurs at a higher fraction of the number of cycles to liquefaction (for instance, with CSR $=0.089$, $50 \%$ of the effective stress loss occurs before the specimen has undergone about $60 \%$ of the cycles required to reach liquefaction, versus $80 \%$ of the cycles to liquefaction in the case of $\mathrm{CSR}=0.118$ ). This does not imply that the rate of generation of excess pore pressure increases with decreasing CSR - the opposite is true as shown in Figure 6 - but is a result of the significant rise in the number of cycles to liquefaction with decreasing CSR.

Figure $7 \mathrm{~b}$ shows that the normalized pore pressure generation of sand-laponite specimens follows a similar trend, i.e. the normalized curves shift downwards with an increase in CSR. However, for CSR values higher than 0.194 the normalized curves plot below the boundary established for clean sands, indicating that the presence of laponite in the sand matrix modifies the patterns usually observed in the excess pore pressure generation of sands. Note that, as discussed in more detail below, this is different than what was previously reported for sand bentonite mixtures by E1 Mohtar et al. [23].

Further insight into the impact of the presence of $1 \%$ laponite can be gained by looking at specific features of the behavior of the specimens during cyclic loading, as done by El Mohtar et al. [23]. Figure 8 shows a plot of excess pore pressure normalized by the pre-shear effective stress $\left(\sigma_{0}^{\mathrm{ee}}\right)$ and axial strain versus the number of cycles for a test conducted on clean sand. The response in Figure 8 is qualitatively representative of what is observed in all the tests on clean sand and sand-laponite specimens that reached liquefaction. The figure identifies several parameters that can be extracted from the cyclic shear stage of each test. In particular, the following five parameters are used in this paper to compare the behavior of clean sand and sandlaponite specimens: 
- $\Delta \mathrm{U}_{\mathrm{m}}$, the rate of mean excess pore pressure generation in the plateau region;

- $\quad \mathrm{N}_{\text {Trigg, }}$, the number of cycles at which the axial strain exceeds $0.1 \%$ (this strain threshold is chosen here as it is considered to represent the transition from small to large strains);

- $\Delta \mathrm{u}_{\text {Trigg, }}$, the excess pore pressure measured at $\mathrm{N}_{\text {Trigg; }}$;

- $\quad \mathrm{N}_{\mathrm{Liq}}$, the number of cycles to liquefaction, based on the initial liquefaction criterion;

- $\left(\mathrm{N}_{\mathrm{Liq}}-\mathrm{N}_{\text {Trigg }}\right)$ the number of cycles between triggering of axial strains and liquefaction.

Table 1 summarizes these parameters for all tests conducted on dry-mixed specimens of sand and laponite. A similar approach was taken by El Mohtar et al. [23] to compare differences in the pore pressure development behavior of clean sand and sand-bentonite specimens (see more below). In place of $\mathrm{N}_{\text {Trigg }}$ these authors employed $\mathrm{N}_{\text {Acc }}$, the number of cycles at the end of the plateau region in correspondence to which the excess pore pressure development accelerates. Accordingly, they utilized $\Delta \mathrm{u}_{\text {Acc }}$, in place of $\Delta \mathrm{u}_{\text {Trigg }}$, and $\left(\mathrm{N}_{\text {Liq }}-\mathrm{N}_{\text {Acc }}\right)$ in place of $\left(\mathrm{N}_{\text {Liq }}-\mathrm{N}_{\text {Trigg }}\right)$. $\mathrm{N}_{\text {Trigg }}$ is preferred here as its identification is more straightforward than $\mathrm{N}_{\text {Acc. }}$.

The effect of CSR and the presence of $1 \%$ laponite on the number of cycles to liquefaction $\left(\mathrm{N}_{\mathrm{Liq}}\right)$ was examined in Figure 4. Figures 9a-d illustrate the differences between the response of clean sand and sand-laponite specimens prior to reaching liquefaction by plotting the CSR versus $\Delta \mathrm{U}_{\mathrm{m}}, \mathrm{N}_{\text {Trigg, }} \Delta \mathrm{u}_{\text {Trigg }}$ and $\left(\mathrm{N}_{\text {Liq }}-\mathrm{N}_{\text {Trigg }}\right)$.

Figure 9a shows that for both clean sand and sand-laponite specimens, the rate of excess pore pressure generation in the "plateau" increases as the CSR increases. More interestingly, it is observed that sand-laponite specimens require a greater CSR to produce the same rate of excess pore pressure generation compared to clean sand. Given that the rise in excess pore pressure is ultimately related to the tendency of sand particles to displace relative to each other, this suggests that the presence of laponite reduces the mobility of the sand grains. This reduction of particle mobility delays the excess pore pressure generation, decreasing the rate of generation and the corresponding loss of effective confinement, compared to clean sands.

Figures $9 \mathrm{~b}$ and $9 \mathrm{c}$ show that - for both clean sand and sand-laponite specimens - the number of cycles at which the axial strains are triggered, and the excess pore pressure that the specimen can withstand before the occurrence of large deformations, decrease with increasing CSR. Also, in this case, the presence of laponite affects the response of the specimen: for the same CSR, sand-laponite specimens can withstand a larger number of cycles before the 
triggering of large axial strains. Moreover, as indicated in Figure 9c, in presence of laponite the specimens can sustain a higher excess pore pressure, and thus a greater effective stress loss, when the axial strains are triggered.

Consistent with the previous observation are the data shown in Figure 9d. They illustrate how, once the axial strains are triggered, the presence of laponite allows the sand to resist more cycles of loading before reaching liquefaction, extending what can be thought of as the "grace" period of the specimen. Overall, the above effects contribute to increasing the liquefaction resistance of the sand-laponite specimens observed in Figure 4.

\subsection{Response during First Loading Cycle}

The data discussed so far pertain to specimens prepared in loose conditions, which would be expected to exhibit contractive behavior as a result of shear. Moreover, the results presented above focused on the behavior of the specimens after the application of a significant number of cycles. However, laponite is observed to impact the response of the specimen from the very early stages of cyclic loading. Figure 10a shows an example of the variation of the deviator stress and the excess pore pressure during this very early stage of the cyclic loading phase. It is observed that there is a slight time lag in the generation of the excess pore pressure, which translates into an offset between the curve of the deviator stress and that of the excess pore pressure of about 0.07 seconds for the test shown. This delay is not unexpected given the very rapid loading. A similar time lag is observed in all the tests, with the tests on clean sand showing marginally lower values than the tests with laponite. Note also that the values of the time lag are generally consistent with predictions made with the method suggested in Bishop and Henkel [43] for deriving the time required for excess pore pressure equalization within a soil specimen (the predictions were made using values of $\mathrm{k}, \mathrm{c}_{\mathrm{v}}$, and $\mathrm{m}_{\mathrm{v}}$ derived from tests on clean sand and sandlaponite specimens $[25,26])$. The above suggests that the clean sand and sand-laponite excess pore pressure data measured during the first quarter cycle may be compared, i.e. are valid on a relative basis, if not in absolute terms.

This comparison is presented in Figure 10b, which shows plots of the CSR as a function of the excess pore pressure generated in the first quarter of the first loading cycle, $\Delta \mathrm{u}_{1 \mathrm{qc}}$, i.e. during the first 0.25 seconds of the shear stage. Figure $10 \mathrm{~b}$ shows that, as expected, for both clean sand and sand-laponite specimens the higher the applied CSR, the higher the excess pore 
pressure generated in this early stage of undrained cyclic loading. More interestingly, the data show that the CSR required to produce the same excess pore pressure is higher in sand-laponite specimens compared to clean sand. The difference is observed to increase with increasing CSR values, overall indicating that the presence of laponite induces a less contractive response. This observation is consistent with recent results from monotonic triaxial tests [44].

\subsection{Effect of Duration or Pre-shear Aging and Percentage of Laponite}

As indicated in Table 1, a limited number of tests on sand-laponite specimens were conducted with shorter ( 1 and 35 hours) and longer (192 hours $\sim 8$ days) duration of the postconsolidation aging stage (tests L13 through L15). As shown in Figure 11, for similar values of CSR (0.146-0.150), the number of cycles to liquefaction increases with aging duration, with the relationship between number of cycles to liquefaction and aging duration well described by an exponential relationship. It should be noted from Table 1 that only one test (L13) was performed following 1 hour of aging. Unfortunately the skeleton relative density for specimen L13 falls above the values for the other tests considered in Figure 11. This, however, does not undermine the conclusion drawn on the effects of aging as, if anything, the results for test L13 overpredict the number of cycles to liquefaction that would be sustained by a specimen with lower $\mathrm{D}_{\text {rsk. }}$. It should also be noted that the number of cycles to liquefaction (5) measured in test L13 is very close to the values measured on clean sand specimens tested at the same relative density and cyclic stress ratio (e.g. see tests $\mathrm{C} 14$ and $\mathrm{C} 15$ in Table 2). This indicates that aging is critical for laponite to improve the cyclic resistance of sand.

Closer examination of the data presented in Table 1 for the tests with different aging times indicates a consistent effect of the duration of aging on the parameters used to describe the stages of excess pore pressure generation. For example, it is seen that the rate of pore pressure generation in the plateau region measured by $\Delta \mathrm{U}_{\mathrm{m}}$ consistently decreases with increasing aging, while $\mathrm{N}_{\text {Trigg }}$ increases with aging. Due to problems encountered in measuring the excess pore pressure during the last portion of the cyclic test on the specimen aged 8 days, $\Delta \mathrm{u}_{\text {Trigg }}$ is not available for this test. For the remaining tests (aging of 1 to 72 hours), the $\Delta \mathrm{u}_{\text {Trigg }}$ data fall in a tight range with no clear trend with aging duration.

The excess pore pressure measured during the first quarter cycle for the aged specimens shows a consistent trend of decreased contractive behavior with increasing aging. Specifically, 
for similar values of CSR, $\Delta \mathrm{u}_{1 \mathrm{qc}}$ goes from $\sim 12$, to $6-7$, to $5 \mathrm{kPa}$ as the aging increases from 1 (Test L13) to 65-72 (Tests L5 and L7) to 192 hours (Test L15).

As summarized in Table 1, six tests were performed on specimens prepared with 3\% (L16 - L19) and 5\% (L20 and L21) laponite by dry mass of the sand. The test conditions varied slightly from those existing in the $1 \%$ laponite tests, in that for these tests the average $\mathrm{D}_{\text {rsk }}$ was $~$ $17 \%$ (with three of the tests having $\mathrm{D}_{\text {rsk }}$ in the $8-11 \%$ range) compared to $\mathrm{D}_{\text {rsk }} \sim 21 \%$ for the $1 \%$ laponite specimens. Moreover, for 5\% laponite, both tests were conducted at a higher aging time (96 hours versus the average 71 hours used for reference tests with 1\% laponite). Despite these differences, based on the summary of the results shown in Table 1, conclusions can be drawn on the effect of the laponite percentage content on the liquefaction resistance, making two distinct comparisons. To start, focusing only on the $1 \%$ and $3 \%$ laponite specimens, one can compare tests L5 (1\% laponite, CSR=0.146, $\left.\mathrm{D}_{\text {rsk }}=15 \%\right)$ and L18 ( $3 \%$ laponite, CSR=0.148, $\left.\mathrm{D}_{\text {rsk }}=11 \%\right)$; despite the slightly higher CSR and slightly lower $\mathrm{D}_{\text {rsk, }}$ test L18 resisted 801 loading cycles before liquefying, compared to 68 for test L5. Examination of the remaining data reported in Table 1 for these two tests also shows that the increase in laponite dosage is associated with: a reduction in $\Delta \mathrm{U}_{\mathrm{m}}$ (from 0.73 to $0.06 \mathrm{kPa}$ /cycle) and an increase in $\mathrm{N}_{\text {Trigg }}$ (from 62 to 788 ), $\Delta \mathrm{u}_{\text {Trigg }}$ (from 64 to $82 \mathrm{kPa}$ ), and $\mathrm{N}_{\mathrm{Liq}}-\mathrm{N}_{\text {Trigg }}$ (from 7 to 13). Second, one can compare the results for three tests performed with $\mathrm{CSR}=0.15$ and 96 hours of post-consolidation aging: one (L19) performed on sand with 3\% laponite, the other two (L20 and L21) on sand with 5\% laponite: test L19 (3\% laponite, $\mathrm{D}_{\mathrm{rsk}}=25 \%$ ) liquefied after 1,345 cycles, while neither L20 nor L21 (both with 5\% laponite and $\mathrm{D}_{\mathrm{rsk}}=18$ and $22 \%$ ) reached liquefaction. This indicates that the trend of increasing liquefaction resistance with increasing laponite content extends to at least 5\% laponite. Collectively, the data above indicate that for the same CSR and aging duration, an increase in the percdentage of laponite translates into an increased number of cycles to liquefaction.

While the data presented above suggest a consistent picture of the effect of increasing the percentage of laponite on excess pore pressure development during cyclic loading, the data sets for the different percentages of laponite differ in some regards. First, it is observed that, unlike what was found for $1 \%$ laponite (Figure $7 b$ ), for the 3\% laponite specimens, the curves of $r_{u}$, the residual excess pore pressure ratio versus $\mathrm{N} / \mathrm{N}_{\mathrm{Liq}}$, fall in the upper range of the clean sand band (see Figure 7c). Comparison of Figures $7 \mathrm{~b}$ and $7 \mathrm{c}$ indicates that the three curves for 3\% laponite with $\mathrm{CSR}=0.146-0.150$ are shifted upwards relative to the curves for $1 \%$ laponite specimens with 
comparable CSR (0.137 and 0.163). This is due to the higher rate of excess pore pressure generation in the first part of the test. This result is consistent with previous observations on the effect of the presence of fines on the excess pore pressure generation behavior reported in the literature (e.g. $[23,45,46])$. As indicated in Table 1, on average, the specimens with $3 \%$ laponite are characterized by skeleton relative density lower than that of the $1 \%$ laponite specimens (with three of them having values lower than any of the $1 \%$ laponite specimens). The upward shift in the curves of $r_{u}$ versus $\mathrm{N} / \mathrm{N}_{\text {Liq }}$ with $3 \%$ laponite cannot be ascribed to this difference, as a reduction in relative density is actually known to have the opposite effect, i.e. to shift the curve downward (e.g. [45]). This is somewhat counterintuitive. While it is true that a larger excess pore pressure is generated at any given cycle $\mathrm{N}$ as the relative density decreases (causing a looser specimen to liquefy earlier), the trend observed in Figure 7c is a by-product of the normalization of $\mathrm{N}$ by $\mathrm{N}_{\mathrm{Liq}}$, as the latter parameter increases with increasing relative density.

Note that given that the $5 \%$ laponite specimens did not reach liquefaction, the curves for these specimens were not included in Figure 7.

An additional aspect that differentiates the 1\% laponite results from those with higher laponite $\%$ is the response during the first loading cycle. The $\Delta \mathrm{u}_{1 \mathrm{qc}}$ data for $3 \%$ laponite fall in the band formed by the $1 \%$ laponite results (see values in Table 1). However, for 5\% laponite the values of $\Delta \mathrm{u}_{1 \mathrm{qc}}$ exceed those measured on the $1 \%$ laponite specimens tested at the same CSR (i.e. for CSR $=0.15 \Delta \mathrm{u}_{1 \mathrm{qc}}=10-12 \mathrm{kPa}$ in tests L20-L21, compared to the average value of $8 \mathrm{kPa}$ obtained from the regression line through the 1\% laponite data in Figure 10a). This indicates a more contractive behavior at least during this very early portion of the cyclic shear stage relative to the $1 \%$ laponite specimens. Moreover, while all other data show a trend of decreasing $\Delta \mathrm{u}_{1 \mathrm{qc}}$ with increasing cyclic resistance, the data for 3\% and 5\% laponite do not follow this trend (e.g. tests L20 and L21, which did not reach liquefaction display amongst the highest measured values of $\left.\Delta \mathrm{u}_{1 \mathrm{qc}}\right)$.

The above observations suggest that the mechanism(s) responsible for the improved resistance to liquefaction may be different in these specimens relative to those with $1 \%$ laponite. This aspect is examined further below.

\section{Comparison to Sand-bentonite Specimens}


Recently, El Mohtar et al. [22,23] studied the effect of the presence of small percentages of bentonite on the cyclic behavior of Ottawa sand. Comparison of the data collected for the sandlaponite specimens to the published results for bentonite provides insight into the role played by the type and dosage of fines.

The testing conditions examined by El Mohtar et al. [22,23] are similar to those considered in this work with regard to the following: dry pluviation method for specimen formation, back-pressure saturation, consolidation to $100 \mathrm{kPa}$, sinusoidal cyclic waveform, cyclic frequency $\sim 1 \mathrm{~Hz}$. The work by El Mohtar et al. [22,23] differs, however, in the following aspects: i) the "dosages" of bentonite examined were larger (3\% and $5 \%$ by dry mass of the sand, compared to $1 \%$ for laponite); ii) the targeted value of the skeleton relative density was higher than that considered in this work $\left(D_{\text {rsk }} \sim 35 \%\right.$ versus $\left.D_{\text {rsk }} \sim 20 \%\right)$; iii) the sand-bentonite specimens were allowed to "rest" for 72 hours prior to the application of backpressure to allow full swelling of the clay; and iii) in the majority of the tests the cyclic shear stage followed a 24 hour post-consolidation period (with additional tests performed extending this aging period). Table 2 summarizes key results from the cyclic tests conducted on sand bentonite specimens, as well as from tests on clean sand specimens of similar skeleton relative density. These data include information presented by El Mohtar et al. [22,23], as well as additional data extracted from the test results.

Figure 12 shows curves describing the relationship between CSR and number of cycles to liquefaction for specimens of: clean sand $\left(\mathrm{D}_{\mathrm{r}} \sim 20 \%\right.$ and $\left.35 \%\right)$, sand with $1 \%$ laponite (average $\mathrm{D}_{\text {rsk }} \sim 21 \%$ ), sand with 3\% bentonite (average $\mathrm{D}_{\text {rsk }} \sim 38 \%$, with 24 and 96 hours aging), and sand with $5 \%$ bentonite (average $\mathrm{D}_{\mathrm{rsk}} \sim 39 \%, 24$ hours aging). The continuous curves through the bentonite and clean sand $\left(\mathrm{D}_{\mathrm{r}} \sim 35 \%\right)$ data are the best fit lines provided by El Mohtar et al. [22] (see data in Table 2). The circular gray symbols are the results for sand-laponite specimens (same as data presented in Figure 4). For clarity, the best fit line shown in Figure 4 for the sandlaponite results is not shown here. Only limited data for higher dosages of laponite are included in this figure (they pertain to tests L19-L21; see larger circular gray symbols). For clarity, the remaining data are omitted as they pertain to significantly lower values of skeletal relative density (see Table 1). As in Figure 4, the symbols with an arrow indicate that the test was terminated after the specimen reached a plateau of constant pore pressure generation, without reaching liquefaction. 
The data presented in Figure 12 clearly show the well documented (e.g. [24,40,47]) effect of relative density on the cyclic resistance of clean sand (compare clean sand data for Dr $35 \%$ and $\operatorname{Dr} 20 \%)$; and the various data sets - clean sand, sand-laponite (1\%) and sand-bentonite (3\% and $5 \%$ ) - show the expected trends of decreasing number of cycles to liquefaction with increasing CSR. More importantly, Figure 12 shows that relative to the clean sand specimens, the addition of the bentonite or laponite fines translates into an increase in the cyclic resistance of at least one order of magnitude at any CSR, and an increase in the threshold CSR in correspondence to which liquefaction is never reached. Despite the lower skeleton relative density, and the smaller clay percentage, the data for $1 \%$ laponite fall on the band formed by the $3 \%$ and $5 \%$ bentonite 24 -hour aging results.

The plots presented in Figure 13 provide additional insight into the role played by the fines, and the relative "performance" of bentonite and laponite fines. As done earlier in Figure 9, Figures $13 \mathrm{a}-\mathrm{d}$ plot the mean excess pore pressure generation rate in the plateau region $\left(\Delta \mathrm{U}_{\mathrm{m}}\right)$, the number of cycles when an axial strain greater than $0.1 \%$ is triggered $\left(\mathrm{N}_{\text {Trigg }}\right)$, the excess pore pressure at $\mathrm{N}_{\text {Trigg }}\left(\Delta \mathrm{u}_{\text {Trigg }}\right)$, and the "grace period" $\left(\mathrm{N}_{\text {Liq }}-\mathrm{N}_{\text {Trigg }}\right)$. The continuous lines represent regression fits through the various data sets while the sand-laponite results are presented with gray circular symbols (again no best fit line shown here for this data set).

For all types of specimens examined (clean sand, sand bentonite and sand laponite) the same trends of increasing $\Delta \mathrm{U}_{\mathrm{m}}$, and decreasing $\mathrm{N}_{\text {Trigg }}, \Delta \mathrm{u}_{\text {Trigg }}$ and $\left(\mathrm{N}_{\text {Liq }}-\mathrm{N}_{\text {Trigg }}\right)$ with increasing CSR are observed. Comparison of the two data sets for clean sand also highlights the effect of changes in relative density on these same excess pore pressure generation parameters.

The figures illustrate the impact of the presence of bentonite fines on the pore pressure generation behavior during cyclic loading previously in part highlighted by El Mohtar et al. [23]. In brief, as already summarized above for laponite, relative to the behavior observed for clean sand specimens of equal Drsk, the presence of bentonite fines reduces the generation of excess pore pressure in the plateau region (Figure 13a), increases the number of cycles $\left(\mathrm{N}_{\text {Trigg }}\right)$ required to trigger axial strains greater than $0.1 \%$ (Figure 13b), allows the specimen to tolerate a greater effective stress loss before $\mathrm{N}_{\text {Trigg }}$ is reached (Figure 13c), and extends the number of cycles that the specimen can sustain after $\mathrm{N}_{\text {Trigg }}$ and before liquefaction is reached $\left(\mathrm{N}_{\text {Liq }}-\mathrm{N}_{\text {Trigg }}\right)$ (Figure 13d). Moreover, as seen above for laponite, increases in bentonite percentage or aging duration are associated with a further improvement in response. 
It is of interest to examine the position of the laponite data relative to the results for bentonite. Figures 13a-c show that, in the case of $1 \%$ laponite, the results for $\Delta \mathrm{U}_{\mathrm{m}}, \mathrm{N}_{\text {Trigg }}$, and

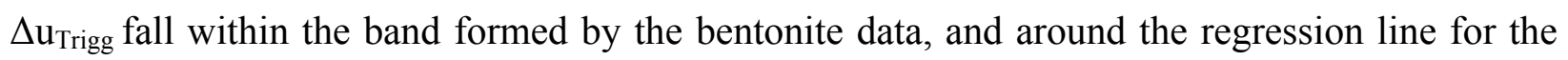
$5 \%$ bentonite specimens aged $24 \mathrm{hrs}$. Given the lower skeleton relative density and smaller percentage of added plastic fines, the similar performance of these specimens in reducing the generation of excess pore pressure during cyclic loading, suggests that plasticity of the fines and aging duration, rather than fines percentage are the controlling factors.

Comparison of the laponite and bentonite results also highlights some important differences between these two data sets. First, Figure 13d shows that in terms of $\mathrm{N}_{\mathrm{Liq}}-\mathrm{N}_{\text {Trigg, }}$, the performance of the sand-laponite (1\%) specimens is consistently inferior to that of all the specimens with bentonite, although still better than that of clean sand with $\mathrm{Dr}_{\mathrm{r}}$ as high as $35 \%$. This means that once axial strains are triggered, sand-laponite specimens have a more limited capability relative to sand-bentonite specimens to withstand additional loading cycles.

A second difference between the two data sets is observed in the values of excess pore pressure measured during the first loading cycle $\left(\Delta \mathrm{u}_{1 \mathrm{qc}}\right) . \Delta \mathrm{u}_{1 \mathrm{qc}}$ data derived from the cyclic tests on sand-bentonite mixtures reported in [22,23] are summarized in Table 2 and plotted in Figure 14 alongside data for clean sand with similar skeleton relative density. Also shown is the regression line through the data for clean sand with lower relative density previously shown in Figure 10. Figure 14 shows that, as expected, for all specimen types there is a general trend of increasing $\Delta \mathrm{u}_{1 \mathrm{qc}}$ with CSR, and that specimens of the same kind (e.g. clean sand) exhibit decreasing $\Delta \mathrm{u}_{1 \mathrm{qc}}$ with increasing $\mathrm{D}_{\text {rsk }}$ at the same CSR (e.g. compare clean sand with $\mathrm{D}_{\text {rsk }}=20 \%$ and 35\%). More importantly, it is observed that the data for the specimens with 3 and 5\% bentonite ( 24 hours of aging) generally plot to the right of the data for clean sand with similar $\mathrm{D}_{\text {rsk }}(\sim 35 \%)$, with the $5 \%$ bentonite specimens for the most part showing larger $\Delta \mathrm{u}_{1 \mathrm{qc}}$ than the $3 \%$ bentonite specimens at the same CSR. These results indicate that, in contrast to what was shown above for specimens with $1 \%$ laponite, the presence of $3 \%$ and $5 \%$ bentonite induces a slightly more contractive tendency during the very early stages of shearing. This is in agreement with results from undrained monotonic triaxial tests performed on these same materials by El Mohtar et al. [22], which showed an initial more contractive tendency (Note that, as shown in Table 2, this behavior is reversed with extended aging, again consistent with the monotonic data reported in [22]). 
Consistent with this observation are the curves of residual excess pore pressure ratio versus $\mathrm{N} / \mathrm{N}_{\text {Liq }}$ reported for specimens with $3 \%$ and $5 \%$ bentonite in [22]. These data show that the addition of bentonite causes an upward shift of the curves relative to the clean sand, an indication of the higher rate of excess pore pressure generation in the earlier cycles. This observation is in contrast to what is shown in Figures 7a-b for 1\% laponite, but similar to the behavior of the specimens with 3\% laponite (Figure 7c).

Finally, the data presented in Figure 11 and Tables 1-2 suggest that the specimens with $3 \%$ bentonite may be more affected by aging than those with $1 \%$ laponite (e.g. compare increase in cycles to liquefaction as aging increases from 24 hours to 3-4 days).

Overall, these differences are, likely, a reflection of differences between the specimens at the microstructure level.

\section{Hypothesized Mechanisms that Enable Observed Behavior}

The sections above presented the results of cyclic tests performed on sand-laponite specimens and highlighted the impact of the presence of these super plastic fines on the pore pressure generation behavior and the resistance to liquefaction measured in cyclic tests. Additionally, these data were compared to an extensive database collected for sand-bentonite specimens. Table 3 summarizes the main observations made on the response of these materials. The response can be explained based on the fabric formed as a result of the nature and dimension of the clay fines and the specimen preparation procedure.

Because of their highly charged surface, laponite and bentonite particles are electrostatically attracted to the sand surface, and, when mixed dry, tend to coat the topography of the grains. This means that even with very small amounts of clay (and, in the case of laponite, despite the silt size of stacks formed by the laponite crystals in dry conditions), the fines are not hosted in the pore space between the particles, i.e. the fabric formed is not perfectly non-floating. This is supported by measurements of the limiting void ratios in presence of laponite, which show an increase in the skeletal void ratios with as little as $1 \%$ laponite [38].

This observation is in contrast to what occurs in mixtures of sand and "coarser" fines, such as silt, which do not have a tendency to attach to the sand grains. For these materials the upper threshold fines content to prevent a floating fabric has been found to be as high as $20-30 \%$ 
(e.g. [16]). Note also that the laponite contents (1-3\%) found to interfere with direct interparticle contact between the sand grains are significantly lower than the threshold values that would be predicted using the relationship proposed by Mitchell and Soga [48].

In light of this, it is hypothesized that the following two mechanisms are responsible for the behavior observed in the cyclic tests:

(1) bonding/bridging at the particle contacts due to the fines;

(2) formation in the pore space of a pore fluid with solid-like properties as a result of the hydration of the clay particles present in the pore space.

Both these mechanisms can contribute to restraining the mobility of the sand particles during cyclic loading, and thus can account for the improved resistance to liquefaction observed when testing specimens with laponite (and bentonite). The existence of these mechanisms explains not only the increase in cyclic resistance (as measured by a greater $\mathrm{N}_{\mathrm{Liq}}$ at any CSR) relative to clean sand, as well as the changes in the pore pressure parameters $\left(\Delta \mathrm{U}_{\mathrm{m}}, \mathrm{N}_{\text {Trigg, }}\right.$, $\Delta \mathrm{u}_{\text {Trigg }}$ ) examined in this work, but also the observed differences between the different sets of data reported above.

It is proposed that in the specimens with $1 \%$ laponite, the first is the primary mechanism. In this case, even after water is permeated through the specimen, and the clay hydrates, due to the small amount of clay present, the pore space cannot be fully occupied by the clay-based pore fluid. Instead, there is a high concentration of clay in close proximity to the particles, whereas part of the void space continues to be occupied by water. This hypothesis is supported by cryoSEM observations conducted on sand-laponite (1\%) specimens [49], which show higher concentrations of the clay gel in proximity to the particles and the presence of water "pockets." Moreover, hydraulic conductivity measurements on specimens with 1\% laponite [25] suggest partial connectivity between these water filled areas. Under these circumstances the restraint to particle movement during cyclic loading cannot be ascribed to the formation in the sand pore space of a continuous clay gel with solid (elastic) like properties, as suggested for sand-bentonite mixtures $[22,23]$. It is instead due to a form of interparticle bonding/bridging (mechanism (1) above). This hypothesis can explain also the reduction in contractive tendency observed during the first loading cycle (Figure 10). Moreover, it is consistent with the results of resonant column 
tests on specimens with $1 \%$ laponite [38], which show an increase in $G_{\max }$ relative to clean sand specimens with the same skeleton relative density.

Higher dosages of either laponite or bentonite lead to two differences in the fabric of the specimen: greater trapping of fines between the sand grains and extension of the clay gel throughout the pore space.

The larger amounts of clay trapped between the sand grains limit bridging between the particles. Following flushing of the specimen with water, this leads to the formation of what has been referred in [28] as a "quasi-floating" fabric, with a soft clay layer between the sand grains. This fabric has been shown to explain the reduction in peak friction angle [22] and in in shear stiffness $\left(\mathrm{G}_{\max }\right)[22,50]$ measured in sand-bentonite specimens relative to clean sand. It can also explain the increase in contractive tendency compared to clean sand measured in sand-bentonite specimens during the first loading cycle (Figure 14).

The hypothesis of the formation of a thin softer layer between the sand particles in presence of bentonite can be extended to specimens with 3\% and 5\% laponite. It is supported by observed similarities between these sets of data. These include: (i) the position of the residual excess pore pressure ratio curves (Figure 7c); (ii) the excess pore pressure values measured during the first loading cycle (Table 1) which equal or exceed the values observed for $1 \%$ laponite; and (iii) the reported [38] reduction in $\mathrm{G}_{\max }$ measured on specimens with $3 \%$ and $5 \%$ laponite at the same confining stress used in this study compared to both clean sand specimens and specimens with $1 \%$ laponite.

Overall, the above suggests that mechanism (1) likely plays a small, if any, role in the increase in liquefaction resistance observed in the specimens with $3 \%$ and $5 \%$ laponite or bentonite. For these specimens the second mechanism outlined above appears to be, instead, responsible for this behavior. It is enabled by the second difference that arises in the specimen fabric due to the presence of higher dosages of laponite or bentonite, i.e. the extension throughout the pore space of the clay gel formed following permeation of the specimens by water. Phase relations calculations and swelling measurements $[28,38]$ show that for the values of relative density examined, approximately $3 \%$ of bentonite or laponite is required for the pore space to be fully occupied by the clay after swelling. Evidence of the more complete extension of the gel in the pore space is, for example, the ten-fold decrease in hydraulic conductivity $\left(\mathrm{k}_{\mathrm{v}}\right)$ measured in specimens with $5 \%$ bentonite [28] relative to specimens with $1 \%$ laponite [25]. 
Analysis of the mechanical behavior of the laponite and bentonite gels formed in the sand pore space $[27,51]$ shows that these materials exhibit essentially solid-like behavior up to shear strains of $10 \%$ or greater. This has led to propose [27] that up to these magnitudes of shear strain, the clay gel is able to restrain any movement of the sand grains during cyclic loading. This suggests that through mechanism (2) the specimens can sustain greater deformation before reaching failure, compared to mechanism (1). This would explain the fact that specimens with $1 \%$ laponite consistently exhibit shorter "grace periods," as measured by the number $\mathrm{N}_{\mathrm{Liq}}-\mathrm{N}_{\text {Trigg }}$, compared to the specimens with higher dosages of clay (Figure 13d).

\section{Conclusions}

This paper presents the results of a cyclic triaxial testing program conducted on loose specimens of clean sand and sand containing small amounts (1-5\% by dry mass of the sand) of laponite. The objectives of the work were to quantify the impact of this highly plastic nano-clay on the cyclic behavior of the sand, and compare the results to those for clean sand as well as to data from a previous study using bentonite.

The tests show that specimens with 1\% laponite present a cyclic resistance, as measured by the number of cycles to reach $100 \%$ of excess pore pressure development, more than one order of magnitude larger relative to the clean sand tested under similar testing conditions (cyclic stress ratio and skeleton relative density).

Sand-laponite (1\%) and clean sand specimens present similar patterns in the excess pore pressure generation and axial strain response during cyclic shear. However, the presence of $1 \%$ laponite is observed to impact the pore pressure development throughout the entire cyclic loading stage: it decreases the rate of excess pore pressure development $\left(\Delta U_{m},\right)$ in the early portion of the test (plateau region); it increases the number of cycles $\left(\mathrm{N}_{\text {Trigg }}\right)$ and pore pressure $\left(\Delta \mathrm{u}_{\text {Trigg }}\right)$ measured when large axial strains are initiated; and extends the specimen "s "grace period," i.e. the number of cycles that it can sustain after large strains are triggered and before liquefaction occurs $\left(\mathrm{N}_{\text {Liq }}-\mathrm{N}_{\text {Trigg }}\right)$.

The presence of $1 \%$ laponite also produces a change in the response of sands at early stages of cyclic loading, inducing lower excess pore pressure during the first loading cycle, evidence of the reduced contractiveness of the material. This small addition of laponite also has a 
profound effect on the residual excess pore pressure ratio curves $\left(r_{u}\right.$ vs. N/N $\mathrm{N}_{\text {Liq }}$ ), which fall outside of the limits proposed in the literature for clean sands.

The effectiveness of laponite in improving the cyclic resistance hinges on allowing it to age, and further improvements in behavior are observed as the specimen "s pre-shear aging period is extended.

Higher dosages (3-5\%) of laponite cause further increase in cyclic resistance, and have a consistent impact on the parameters used to describe the excess pore pressure generation behavior, in particular reducing $\Delta \mathrm{U}_{\mathrm{m}}$, and increasing $\mathrm{N}_{\text {Trigg }}$ and $\mathrm{N}_{\mathrm{Liq}}-\mathrm{N}_{\text {Trigg }}$.

There are similarities in the behavior of sand-bentonite and sand-laponite specimens. Collective analysis of the sand-laponite and sand-bentonite results suggests that plasticity of the fines and aging duration, rather than fines percentage, are the controlling factors.

Two mechanisms are proposed to explain the behaviors observed in sand-laponite and sand-bentonite specimens: (1) bonding/bridging at the particle contacts due to the laponite/bentonite fines; and (2) formation in the pore space of a pore fluid with solid like properties, as a result of the hydration of the clay present in the pore space. These mechanisms can both account for the reduced mobility of the sand particles during cyclic loading relative to clean sands.

Analysis of the results of the experimental program documented in this paper suggests that the first mechanism controls the behavior of specimens with $1 \%$ laponite, while the second is responsible for the increase in cyclic resistance observed with higher dosages of either laponite or bentonite.

\section{ACKNOWLEDGEMENTS}

This research was partially funded by the National Science Foundation, Geomechanics and Geotechnical Systems Program, under grant CMS-0928679. Partial funding for the first author was provided by the „Gestion propia scholarship program of the National Committee of Science and Technology of Chile (CONICYT). These sources of support are gratefully acknowledged. Appreciation is extended to Professor Vince Drnevich of Purdue University and the two anonymous reviewers who provided thoughtful comments that led to significantly improving the manuscript. 


\section{REFERENCES}

1] De Alba P, Chan CK, Seed HB. Determination of soil liquefaction characteristics by large-scale laboratory tests. Report No. EERC 75-14. May 1975. Berkeley, CA: 1975.

[2] Ishihara K. Liquefaction and flow failure during earthquakes. Geotechnique 1993;43:351415.

[3] Poulos SJ, Castro G, France JW. Liquefaction evaluation procedure. J Geotech Eng 1985;111:772-92. doi:10.1061/(ASCE)0733-9410(1985)111:6(772).

[4] Verdugo R, Gonzalez J. Liquefaction-induced ground damages during the 2010 Chile earthquake. Soil Dyn Earthq Eng 2015; 79:280-295. doi:10.1016/j.soildyn.2015.04.016

[5] Castro G, Poulos SJ. Factors affecting liquefaction and cyclic mobility. J Geotech Eng Div 1977;103:501-6.

[6] Alarcon-Guzman A, Leonards GA, Chameau JL. Undrained monotonic and cyclic strength of sands. J Geotech Eng 1988;114:1089-109. doi:10.1061/(ASCE)07339410(1988)114:10(1089).

[7] Verdugo R, Ishihara K. The steady state of sandy soils. Soils Found 1996;36:81-91.

[8] Vaid YP, Sivathayalan S. Static and cyclic liquefaction potential of Fraser Delta sand in simple shear and triaxial tests. Can Geotech J 1996;2:281-9.

[9] Troncoso J, Verdugo R. Silt content and dynamic behavior of tailings sands. In: Idriss IM, editor. XI Int. Conf. Soil Mech. Found. Eng., San Francisco: Balkema; 1985, p. 1311-4.

[10] Vucetic M, Dobry R. Effect of soil plasticity on cyclic response. J Geotech Eng 1991;117:89-107.

[11] Clough GW, Iwabuchi J, Rad NS, Kuppusamy T. Influence of cementation on liquefaction of sands. J Geotech Eng 1989;115:1102-17.

[12] Lade P V, Yamamuro JA. Effects of nonplastic fines on static liquefaction of sands. Can Geotech J 1997;34:918-28. doi:10.1139/t97-052.

[13] Guo T, Prakash S. Liquefaction of silts and silt-clay mixtures. J Geotech Geoenvironmental Eng 1999;5:706-10.

[14] Thevanayagam S, Fiorillo M, Liang J. Effect of non-plastic fines on undrained cyclic strength of silty sands. In: Pak R, Yamamuro J, editors. GeoDenver 2000, Denver: American Society of Civil Engineers; 2000, p. 77-91. doi:http://dx.doi.org/10.1061/40520(295)6. 
[15] Yamamuro J, Covert K. Monotonic and cyclic liquefaction of very loose sands with high silt content. J Geotech Geoenvironmental Eng 2001;127:314-24.

[16] Polito CP, Martin JR. Effects of nonplastic fines on the liquefaction resistance of sands. J Geotech Geoenvironmental Eng 2001;20:408-15.

[17] Wang GX, Kuwano J. Modeling of strain dependency of shear modulus and damping of clayey sand. Soil Dyn Earthq Eng 1999;18:463-71. doi:10.1016/S0267-7261(99)00010-X.

[18] Tokimatsu K, Yoshimi Y. Criteria of soil liquefaction with SPT and fines content. Eighth World Conf. Earthq. Eng., San Francisco, CA: Prentice Hall; 1984.

[19] Ishihara K, Koseki J. Discussion on the cyclic shear strength of fines-containing sands. Twelfth Int. Conf. Soil Mech. Found. Eng., Rio de Janeiro, Brazil: Japanese Society of Soil Mechanics and Foundation Engineering; 1989, p. 101-6.

[20] Ishihara K. Soil behaviour in earthquake geotechnics. First Edit. Oxford, UK.: Clarendon Press; 1996.

[21] Saxena SK, Reddy KR, Avramidis AS. Liquefaction resistance of artificially cemented sand. J Geotech Eng 1988;114:1395-413.

[22] El Mohtar CS, Bobet A, Santagata MC, Drnevich VP, Johnston CT. Liquefaction mitigation using bentonite suspensions. J Geotech Geoenvironmental Eng 2013;139:1369-80. doi:10.1061/(ASCE)GT.1943-5606.0000865.

[23] El Mohtar CS, Bobet A, Drnevich VP, Johnston C, Santagata MC. Pore pressure generation in sands with bentonite: from small strains to liquefaction. Géotechnique 2013;64:108-17.

[24] Youd T, Idriss I, Andrus R, Arango I, Castro G, Christian J, et al. Liquefaction resistance of soils: summary report from the 1996 NCEER and 1998 NCEER/NSF workshops on evaluation of liquefaction resistance of soils. J Geotech Geoenvironmental Eng 2001;127:817-33.

[25] El Howayek A. Characterization, Rheology and Microstructure of Laponite Suspensions. Purdue Univ 2011:149.

[26] Ochoa-Cornejo F, Bobet A, Johnston CT, Santagata M, Sinfield J. Liquefaction 50 years after Anchorage 1964; How nanoparticles could help prevent it. Proc. 10th Natl. Conf. Earthq. Eng., 2014, p. 11.

[27] Santagata M, Bobet A, El Howayek A, Ochoa-Cornejo F, Sinfield J V, Johnston CT. Building a nanostructure in the pore fluid of granular soils. Geomech. from Micro to Macro, 2014, p. 1377-83. doi:10.1201/b17395-249 
[28] El Mohtar C. Pore fluid engineering: An autoadaptive design for liquefaction mitigation. Purdue University, 2008.

[29] Mongondry P, Tassin JF, Nicolai T. Revised state diagram of Laponite dispersions. J Colloid Interface Sci 2005;283:397-405. doi:10.1016/j.jcis.2004.09.043.

[30] Tanaka H, Meunier J, Bonn D. Nonergodic states of charged colloidal suspensions: Repulsive and attractive glasses and gels. Phys Rev E 2004;69:031404. doi:10.1103/PhysRevE.69.031404.

[31] Ruzicka B, Zaccarelli E. A fresh look at the Laponite phase diagram. Soft Matter 2011;7:1268. doi:10.1039/c0sm00590h.

[32] Mourchid A, Delville A, Lambard J, Lecolier E, Levitz P. Phase diagram of colloidal dispersions of anisotropic charged particles: equilibrium properties, structure, and rheology of laponite suspensions. Langmuir 1995:1942-50.

[33] Joshi YM, Reddy GR, Kulkarni A, Kumar N, Chhabra R. Rheological behaviour of aqueous suspensions of laponite: new insights into the ageing phenomena. Proc R Soc 2008:469-89.

[34] Carraro, JAH., Bandini, P.,Salgado, R. Liquefaction resistance of clean and nonplastic silty sands based on cone penetration resistance." J Geotech Geoenvironmental Eng 2003. 129:965-76. doi:10.1061/(ASCE)1090-0241(2003)129:11(965)

[35] Arango, I., Lewis, M. R., and Kramer, C. Updated liquefaction potential analysis eliminates foundation retrofitting of two critical structures. Soil Dyn. Earthquake Eng 2000; 20:17-25. doi:10.1061/S0267-7261(00)00034-8.

[36] Andrus, R. D., Hayati, H., Mohanan, N. P.. Correcting liquefaction resistance of aged sands using measured to estimated velocity ratio." J Geotech Geoenvironmental Eng 2009; 135:735-744. doi:10.1061/(ASCE)GT.1943-5606.0000025.

[37] Hayati, H. Andrus, R. Updated liquefaction resistance correction factors for aged sands. J Geotech Geoenvironmental Eng 2009;135:19-1380. doi:10.1061/(ASCE)GT.19435606.0000118 .

[38] Ochoa-Cornejo F. Cyclic behavior of sands with superplastic fines. Purdue University 2015:134.

[39] Castro G. Liquefaction of sands. Harvard University, 1969.

[40] Ladd C. Specimen preparation and liquefaction of sands. J Geotech Eng Div 1974;100:1180-4. 
[41] Finn WD, Pickering JD, Bransby P.L. Sand liquefaction in triaxial and simple shear tests. J Soil Mech Found Div 1971.

[42] Lee KL, Albaisa A. Earthquake induced settlements in saturated sands. J Geotech Geoenvironmental Eng 1974;100:387-406.

[43] Bishop A, Henkel DJ. The measurement of soil properties in the triaxial test. Second. London, UK: Edward Arnold Ltd.; 1962.

[44] Getchell A. Effect of Pore Fluid Rheology on the Static Response of Sand. Purdue Univ 2015 (in progress).

[45] Polito, C.P.,. Green, R.A., Lee, J.. 2008. Pore pressure generation models for sands and silty soils subjected to cyclic loading." J Geotech Geoenvironmental Eng 2008; 134 : 1490-1500. doi:10.1061/(ASCE)1090-0241(2008)134:10(1490).

[46] Derakhshandi, M., Rathje, E.E. Hazirbaba, E.E. Mirhosseini, S.M. The effect of plastic fines on the pore pressure generation characteristics of saturated sands. Soil Dyn Earthq Eng 2007; 28: 376-86. doi:10.1016/j.soildyn.2007.07.002.

[47] Lee KL, Fitton JA. Factors affecting the cyclic loading strength of soil. Vib. Eff. Earthquakes Soils Found., vol. 1, San Francisco, CA: Philadelphia; 1968, p. 71-95.

[48] Mitchell JK, Soga K. Fundamentals of Soil Behavior. $3^{\text {rd }}$ Ed. Hoboken, NK: John Wiley \& Sons; 2005.

[49] El Howayek A, Bobet A, Johnston CT, Santagata M, Sinfield JV. Microstructure of sandlaponite-water systems using cryo-SEM. Proceedings 2014 Geo-Congress: GeoCharacterization and Modeling for Sustainability, Atlanta, February 2014

[50] El Mohtar CS, Santagata M., Bobet A, Drnevich VP, Johnston C, Effect of plastic fines on the small strain stiffness of sands. In Burns et al. (Eds.) $4^{\text {th }}$ International Symposium on Deformation Characteristics of Geomaterials (IS-Atlanta) 2014. Vol. 1: 245-251, IOS Press, Netherlands.

[51] Santagata' MC, Clarke JP, Bobet' A, Drnevich VP, El Mohtar CS, Huang PT, Johnston CT. Rheology of concentrated bentonite dispersions treated with sodium pyrophoshate for application in mitigating earthquake induced liquefaction. Applied Clay Science 2014; 99: 24-34. 


\section{LIST OF TABLES}

Table 1. Summary of testing program and select results from tests on sand-laponite specimens and clean sand specimens

Table 2. Select results for clean sand and sand-bentonite specimens (data from [22,23,28])

Table 3. Summary of observations on cyclic behavior of sand-laponite and sand-bentonite specimens

\section{LIST OF FIGURES}

Figure 1. a) Structure of laponite and b) geometry of individual laponite particle

Figure 2. Undrained cyclic response of clean sand sheared with $\mathrm{CSR}=0.096$ (Test CS3): (a) deviatoric stress, (b) axial strain and (c) excess pore pressure ratio versus number of cycles; (d) stress path

Figure 3. Undrained cyclic response of sand-laponite specimen sheared with CSR=0.138 (Test L2) (a) deviatoric stress (b) axial strain (c) excess pore pressure ratio versus number of cycles and (d) stress path

Figure 4. Cyclic resistance of clean sand and sand-laponite specimens (1\%) $\left(\mathrm{Dr}_{\mathrm{sk}}=15 \%-25 \%\right)$

Figure 5. Comparison between number of cycles to liquefaction determined using initial liquefaction criterion versus 5\% axial strain double amplitude criterion

Figure 6. Excess pore pressure ratio during cyclic loading: (a) clean sand versus sand-laponite specimens; (b) sand-laponite specimens sheared at different CSR

Figure 7. Residual excess pore pressure ratio $\left(\mathrm{r}_{\mathrm{u}}\right)$ versus $\mathrm{N} / \mathrm{N}_{\text {Liq }}$ for specimens of (a) clean sand, (b) sand with $1 \%$ laponite, and (c) sand with $3 \%$ laponite

Figure 8. Stages of excess pore pressure generation and axial strain development during undrained cyclic triaxial loading

Figure 9. CSR versus (a) $\Delta \mathrm{U}_{\mathrm{m}}$; (b) $\mathrm{N}_{\text {Trigg; }}$ (c) $\Delta \mathrm{u}_{\text {Trigg }}$; and (d) $\mathrm{N}_{\text {Liq }}-\mathrm{N}_{\text {Trigg }}$

Figure 10. (a) Example of variation of deviator stress and pore pressure during first half cycle of cyclic shear phase, and (b) CSR versus excess pore pressure generated in the first quarter of the first loading cycle $\left(\Delta \mathrm{u}_{1 \mathrm{qc}}\right)$

Figure 11. Increase in cycles to liquefaction with post-consolidation aging time of sand-laponite (1\%) specimens (Tests L5, L6, L7, L13, L14, L15)

Figure 12. CSR versus number of cycles to liquefaction: comparison between clean sand, sand-laponite and sand-bentonite specimens (sand-bentonite data from [22]) 
Figure 13. Comparison between clean sand, sand-laponite and sand-bentonite results: CSR versus (a) $\Delta \mathrm{U}_{\mathrm{m}}$; (b) $\mathrm{N}_{\text {Trigg }}$; (c) $\Delta \mathrm{u}_{\text {Trigg }}$; (d) $\mathrm{N}_{\text {Liq }}-\mathrm{N}_{\text {Trigg }}$ (sand-bentonite data from [23])

Figure 14. CSR versus excess pore pressure generated in the first quarter of the first loading cycle: comparison between clean sand and sand-bentonite specimens 
Table 1 - Summary of testing program and select results from tests on sand-laponite specimens and clean sand specimens

\begin{tabular}{|c|c|c|c|c|c|c|c|c|c|c|c|}
\hline Test \# & Fines & $\%$ Fines & $\begin{array}{l}\text { Drsk } \\
(\%) \\
\end{array}$ & $\begin{array}{c}\text { Aging } \\
\text { (h) }\end{array}$ & CSR & $\underset{(100 \% \mathrm{PP})}{\mathbf{N}_{\text {Lig }}}$ & $\begin{array}{l}\Delta \mathrm{U} 1 \mathrm{qc} \\
(\mathrm{kPa})\end{array}$ & $\begin{array}{c}\Delta \mathrm{Um}=\Delta \mathrm{u} / \text { cycle } \\
(\mathrm{kPa} / \text { cycle })\end{array}$ & NTrigg & $\begin{array}{c}\Delta \mathbf{u}_{\text {Trigg }} \\
(\mathrm{kPa})\end{array}$ & NLiq - NTrigg \\
\hline L2 & Laponite & 1 & 15 & 72 & 0.137 & 542 & 6.2 & 0.09 & 535 & 79.8 & 7 \\
\hline L4 & Laponite & 1 & 20 & 69 & 0.143 & 39 & 5.1 & 1.02 & 36 & 63.0 & 3 \\
\hline L5 & Laponite & 1 & 15 & 72 & 0.146 & 68 & 6.0 & 0.73 & 61 & 64.0 & 7 \\
\hline L6 & Laponite & 1 & 30 & 72 & 0.147 & 52 & NA & 0.86 & 50 & 73.5 & 2 \\
\hline L9 & Laponite & 1 & 20 & 72 & 0.165 & 85 & 7.9 & 0.65 & 82 & 82.7 & 3 \\
\hline L10 & Laponite & 1 & 24 & 72 & 0.194 & 32 & 8.4 & 1.48 & 30 & 63.5 & 2 \\
\hline L11 & Laponite & 1 & 20 & 72 & 0.194 & 16 & 9.6 & 3.60 & 14 & 72.0 & 2 \\
\hline L12 & Laponite & 1 & 20 & 72 & 0.239 & 3 & 12.6 & 34.04 & 2 & 42.0 & 1 \\
\hline L13 & Laponite & 1 & 31 & 1 & 0.150 & 5 & 11.8 & 3.52 & 5 & 64.7 & $<1$ \\
\hline L18 & Laponite & 3 & 11 & 68 & 0.148 & 801 & 6.0 & 0.06 & 788 & 82.0 & 13 \\
\hline L19 & Laponite & 3 & 25 & 96 & 0.150 & 1345 & 8.6 & 0.03 & 1320 & 75.0 & 25 \\
\hline L20 & Laponite & 5 & 18 & 97 & 0.150 & No Liq & 10.3 & 0.00 & NA & NA & NA \\
\hline L21 & Laponite & 5 & 22 & 96 & 0.150 & No Liq & 11.9 & 0.00 & NA & NA & NA \\
\hline $\mathrm{CS} 1^{*}$ & - & 0 & 13 & 1 & 0.089 & 220 & 5.0 & 0.24 & 218 & 85.0 & 2 \\
\hline $\mathrm{CS} 2^{*}$ & - & 0 & 19 & 1 & 0.090 & 27 & 5.4 & 2.11 & 26 & 65.0 & 1.5 \\
\hline CS3 & - & 0 & 18 & 1 & 0.096 & 118 & 6.1 & 0.49 & 115 & 95.6 & 3 \\
\hline CS4 & - & 0 & 22 & 1 & 0.106 & 22 & 5.6 & 2.78 & 22 & 72.5 & $<1$ \\
\hline CS5 & - & 0 & 25 & 1 & 0.118 & 17 & 3.9 & 3.60 & 17 & 81.2 & $<1$ \\
\hline $\mathrm{CS}^{*}$ & - & 0 & 16 & 1 & 0.125 & 4 & 11.1 & 11.55 & 4 & 44.4 & $<1$ \\
\hline $\mathrm{CS} 7^{*}$ & - & 0 & 18 & 1 & 0.139 & 1 & 14.4 & 17.80 & $<1$ & 19.3 & $<1$ \\
\hline
\end{tabular}

* tests previously reported in [22,23] 
Table 2 - Select results for clean sand and sand-bentonite specimens (data from 22,23,28]

\begin{tabular}{|c|c|c|c|c|c|c|c|c|c|c|c|}
\hline Test \# & Fines & $\%$ Fines & $\begin{array}{l}\text { Drsk } \\
(\%)\end{array}$ & $\begin{array}{l}\text { Aging } \\
\text { (h) }\end{array}$ & CSR & $\begin{array}{c}N_{\text {Liq }} \\
(100 \% \mathrm{PP})\end{array}$ & $\begin{array}{l}\Delta \mathrm{U} 1 \mathrm{qq} \mathrm{c} \\
(\mathrm{kPa})\end{array}$ & $\begin{array}{c}\Delta \mathrm{U}_{\mathrm{m}}=\Delta \mathrm{u} / \text { cycle } \\
(\mathrm{kPa} / \text { cycle })\end{array}$ & NTrigg & $\begin{array}{l}\Delta \mathbf{u}_{\text {Trigg }} \\
(\mathrm{kPa})\end{array}$ & NLiq - NTrigg \\
\hline B1 & Bentonite & 3 & 45 & 24 & 0.100 & 1270 & 5.6 & 0.10 & 825 & 89.5 & 445 \\
\hline B2 & Bentonite & 3 & 36 & 24 & 0.100 & 1493 & 6.5 & 0.07 & 1432 & 85.0 & 61 \\
\hline B3 & Bentonite & 3 & 35 & 24 & 0.125 & 88 & 6.9 & 0.61 & 70 & 56.0 & 18 \\
\hline B4 & Bentonite & 3 & 41 & 24 & 0.150 & 50 & 7.2 & 1.38 & 43 & 64.3 & 7 \\
\hline B5 & Bentonite & 3 & 35 & 24 & 0.150 & 46 & 10.9 & 1.34 & 21 & 47.0 & 25 \\
\hline B6 & Bentonite & 3 & 45 & 24 & 0.160 & 36 & 9.1 & 1.60 & 20 & 45.4 & 16 \\
\hline B7 & Bentonite & 3 & 43 & 24 & 0.180 & 13 & 11.6 & 6.80 & 6 & 57.0 & 7 \\
\hline B8 & Bentonite & 3 & 40 & 24 & 0.200 & 8 & 14.3 & 10.00 & 3 & 50.0 & 5 \\
\hline B9 & Bentonite & 3 & 34 & 24 & 0.200 & 6 & 11.3 & 16.00 & 4 & 50.0 & 2 \\
\hline B10 & Bentonite & 3 & 31 & 96 & 0.200 & 5000 & 10.8 & NA & NA & NA & NA \\
\hline B11 & Bentonite & 3 & 31 & 96 & 0.200 & 185 & 9.2 & 0.21 & 160 & 80.0 & 25 \\
\hline B12 & Bentonite & 3 & 35 & 96 & 0.225 & 40 & 8.7 & 2.20 & 25 & 61.0 & 15 \\
\hline B13 & Bentonite & 3 & 37 & 96 & 0.250 & 8 & 13.0 & 13.40 & 2 & 45.0 & 6 \\
\hline B14 & Bentonite & 5 & 33 & 24 & 0.120 & 5000 & 8.4 & 0.02 & 600 & NA & 4400 \\
\hline B15 & Bentonite & 5 & 33 & 24 & 0.150 & 5000 & 13.6 & 0.02 & 5000 & 60.0 & NA \\
\hline B16 & Bentonite & 5 & 42 & 24 & 0.150 & 180 & 4.9 & 0.54 & 110 & 72.5 & 70 \\
\hline B17 & Bentonite & 5 & 40 & 24 & 0.150 & 100 & 8.7 & 0.36 & 87 & 70.0 & 13 \\
\hline B18 & Bentonite & 5 & 37 & 24 & 0.150 & 400 & 13.3 & 0.24 & 350 & 78.2 & 50 \\
\hline B19 & Bentonite & 5 & 40 & 24 & 0.175 & 30 & 12.8 & 2.17 & 20 & 78.5 & 10 \\
\hline B20 & Bentonite & 5 & 43 & 24 & 0.175 & 20 & 12.4 & 4.97 & 11 & 74.6 & 9 \\
\hline B21 & Bentonite & 5 & 39 & 24 & 0.200 & 12 & 14.8 & 9.63 & 4 & 61.2 & 8 \\
\hline B22 & Bentonite & 5 & 37 & 24 & 0.200 & 15 & 7.5 & 7.13 & 4 & 46.0 & 11 \\
\hline B23 & Bentonite & 5 & 38 & 24 & 0.200 & 10 & 15.1 & 9.71 & 5 & 70.5 & 5 \\
\hline B24 & Bentonite & 5 & 37 & 24 & 0.250 & 5 & 18.4 & 20.00 & 2 & 30.0 & 3 \\
\hline $\mathrm{CS}^{+}$ & - & 0 & 35 & 1 & 0.060 & NA & 2.9 & 0.02 & NA & NA & NA \\
\hline CS9 & - & 0 & 41 & 1 & 0.100 & 154 & 3.8 & 0.36 & 147 & 80.6 & 7 \\
\hline CS10 & - & 0 & 35 & 1 & 0.100 & 85 & 4.3 & 0.58 & 75 & 64.3 & 10 \\
\hline CS11 & - & 0 & 33 & 1 & 0.110 & 57 & 5.6 & 1.06 & 51 & 79.4 & 6 \\
\hline $\mathrm{CS} 12^{*}$ & - & 0 & 35 & 1 & 0.115 & 52 & 7.0 & 1.18 & 50 & 84.5 & 2 \\
\hline CS13 & - & 0 & 35 & 1 & 0.125 & 15 & 6.0 & 5.64 & 12 & 84.9 & 3 \\
\hline CS14 & - & 0 & 32 & 1 & 0.150 & 12 & 5.8 & 2.52 & 9 & 56.5 & 3 \\
\hline CS15 & - & 0 & 37 & 1 & 0.150 & 8 & 6.1 & 9.26 & 5 & 47.0 & 3 \\
\hline
\end{tabular}

ttest suspended after 5000 cycles with constant $\Delta \mathrm{U}_{\mathrm{m}}$ * test from this research program 
Table 3 - Summary of observations on cyclic behavior of sand-Laponite and sand-bentonite specimens

\begin{tabular}{|c|}
\hline 1\% LAPONITE \\
\hline 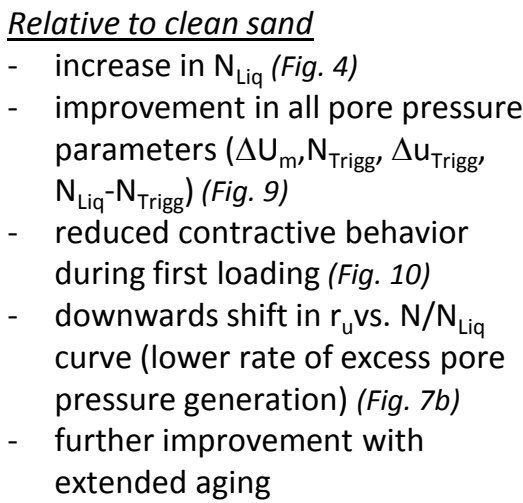 \\
\hline
\end{tabular}

\begin{tabular}{l}
\hline \multicolumn{1}{c}{3 \& 5\% LAPONITE } \\
\hline Relative to 1\% Laponite \\
\hline$-\quad$ increase in $\mathrm{N}_{\text {Liq }}$ (Table 1) \\
improvement in pore pressure \\
parameters ( $\Delta \mathrm{U}_{\mathrm{m}}, \mathrm{N}_{\text {Trigg }} \Delta \mathrm{u}_{\text {Trigg' }}$ \\
$\mathrm{N}_{\text {Liq }}-\mathrm{N}_{\text {TRigg }}$ (Table 1) \\
more contractive behavior during \\
first loading (Fig. 10) \\
upwards shift in $\mathrm{r}_{\mathrm{u}}$ vs. N/ $\mathrm{N}_{\text {Liq }}$ curve \\
(higher rate of excess pore \\
pressure generation) (Fig. $7 c)$ \\
\end{tabular}

\section{3 \& 5\% BENTONITE}

Relative to sand-Laponite

- higher dosage required for equal increase in $\mathrm{N}_{\text {Liq }}$ (Fig. 12)

- longer grace period $\left(\mathrm{N}_{\mathrm{Liq}}-\mathrm{N}_{\text {Trigg }}\right)$ (Fig. 13d)

- more contractive behavior during first loading (Fig. 14)

- $\quad r_{u}$ vs. $N / N_{\text {Liq }}$ curve similar to $3 \%$ laponite (lower rate of excess pore pressure generation)

- greater sensitivity to extended aging 
a)

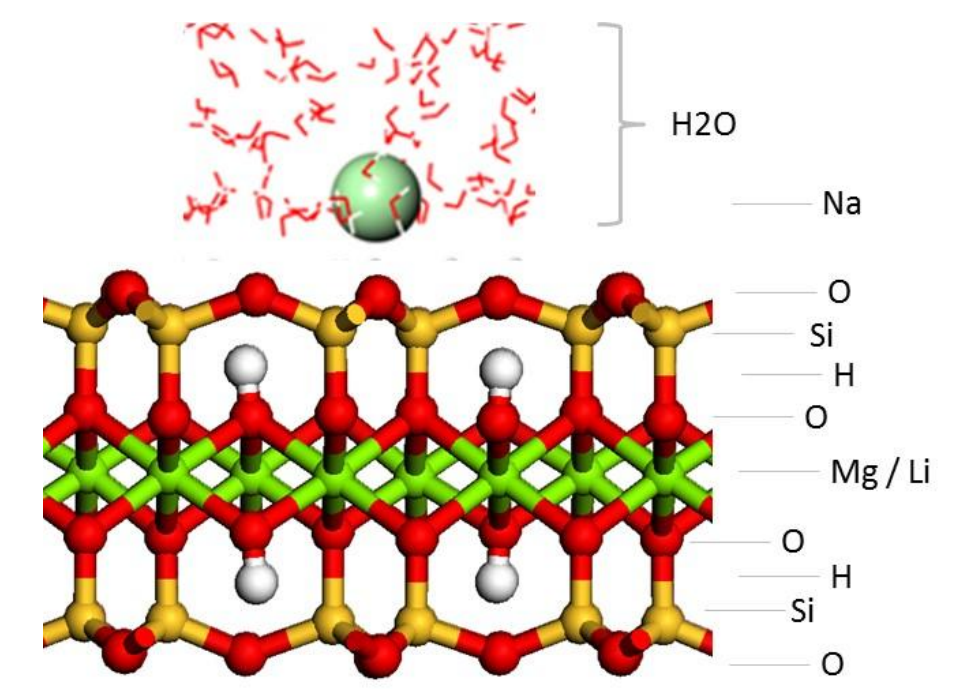

b)

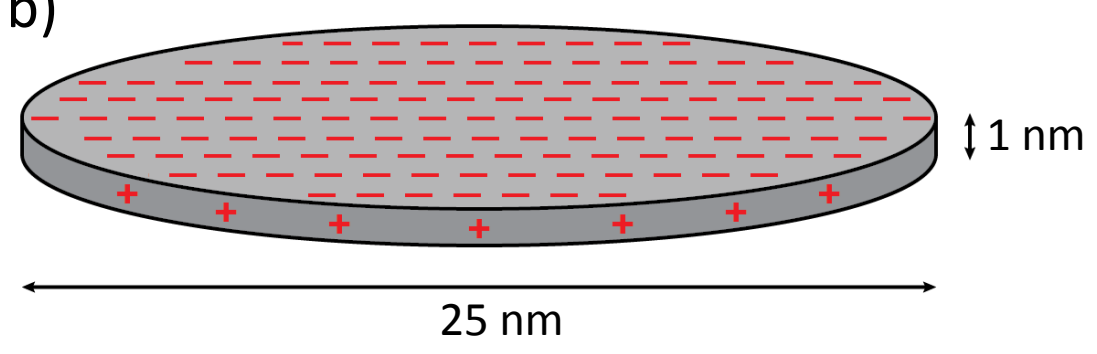

Figure 1. a) Structure of laponite, and b) geometry of individual laponite particle 

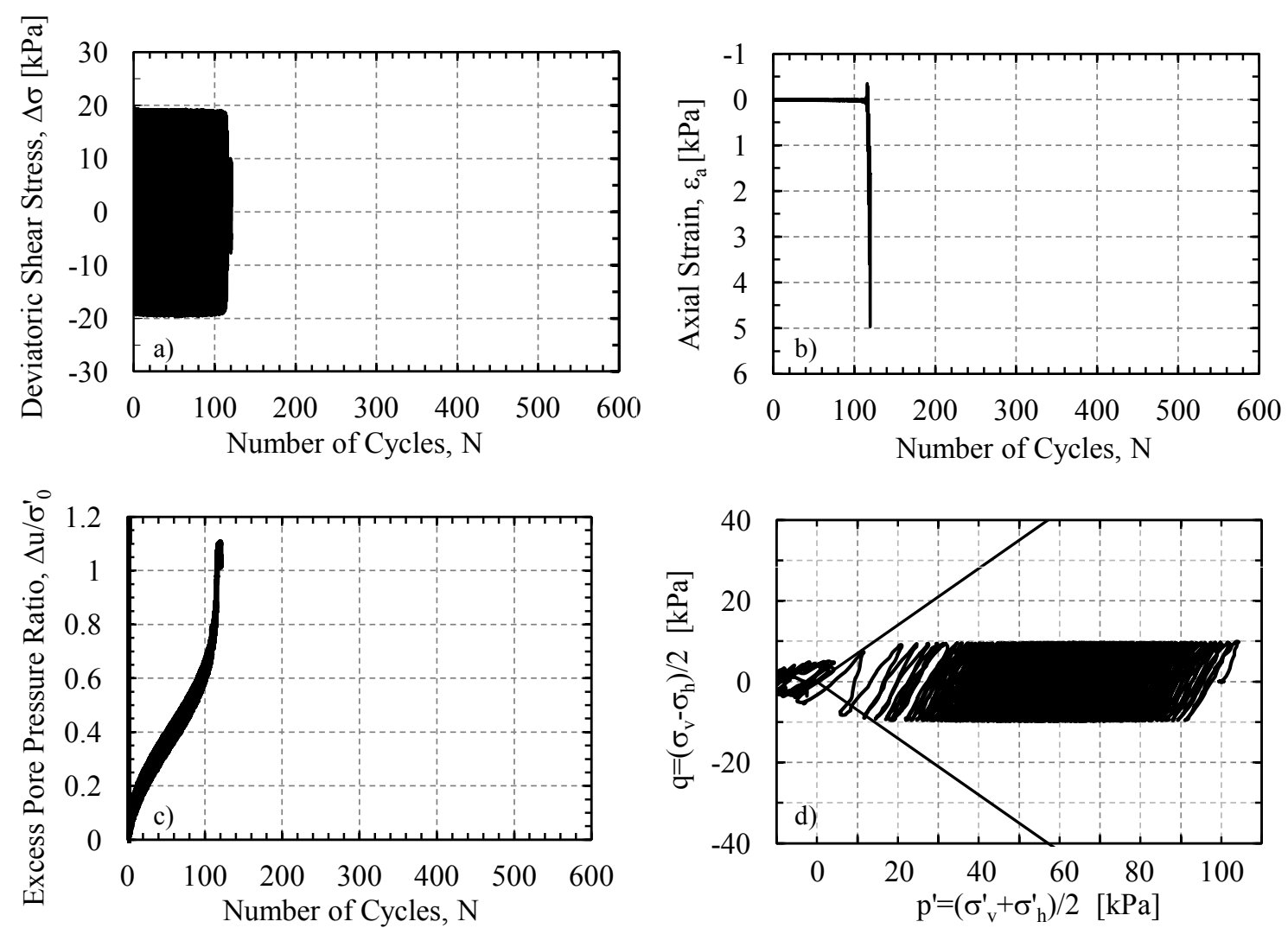

Figure 2. Undrained cyclic response of clean sand sheared with CSR=0.096 (Test CS3): (a) deviatoric stress, (b) axial strain and (c) excess pore pressure ratio versus number of cycles; (d) stress path 



Figure 3. Undrained cyclic response of sand-laponite specimen sheared with CSR=0.137 (Test L2): (a) deviatoric stress (b) axial strain (c) excess pore pressure ratio vs. number of cycles and (d) stress path 


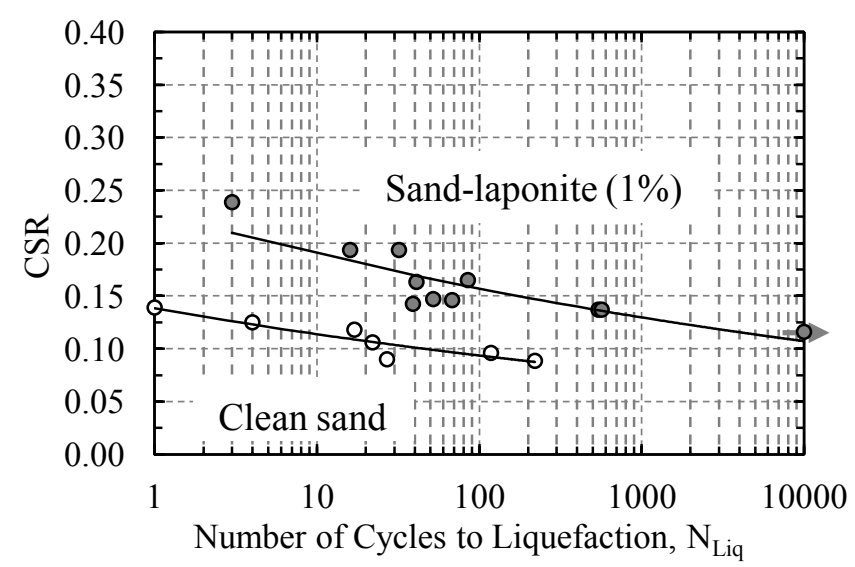

Figure 4. Cyclic resistance of clean sand and sand-laponite specimens (1\%) $\left(\operatorname{Dr}_{\mathrm{sk}}=15 \%-25 \%\right)$ 


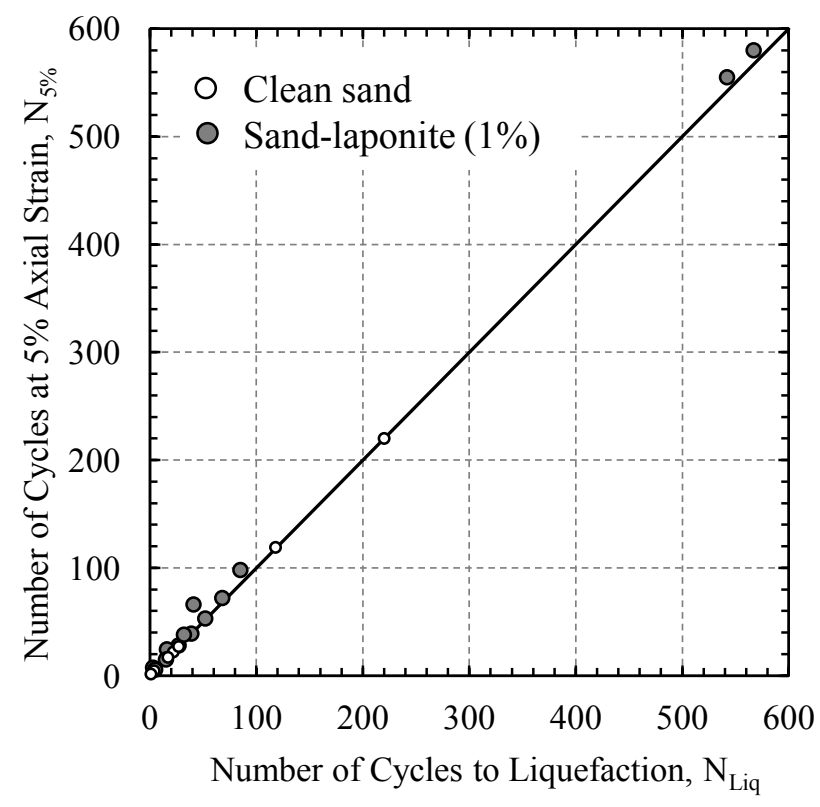

Figure 5. Comparison between number of cycles to liquefaction determined using initial liquefaction criterion versus $5 \%$ axial strain double amplitude criterion 

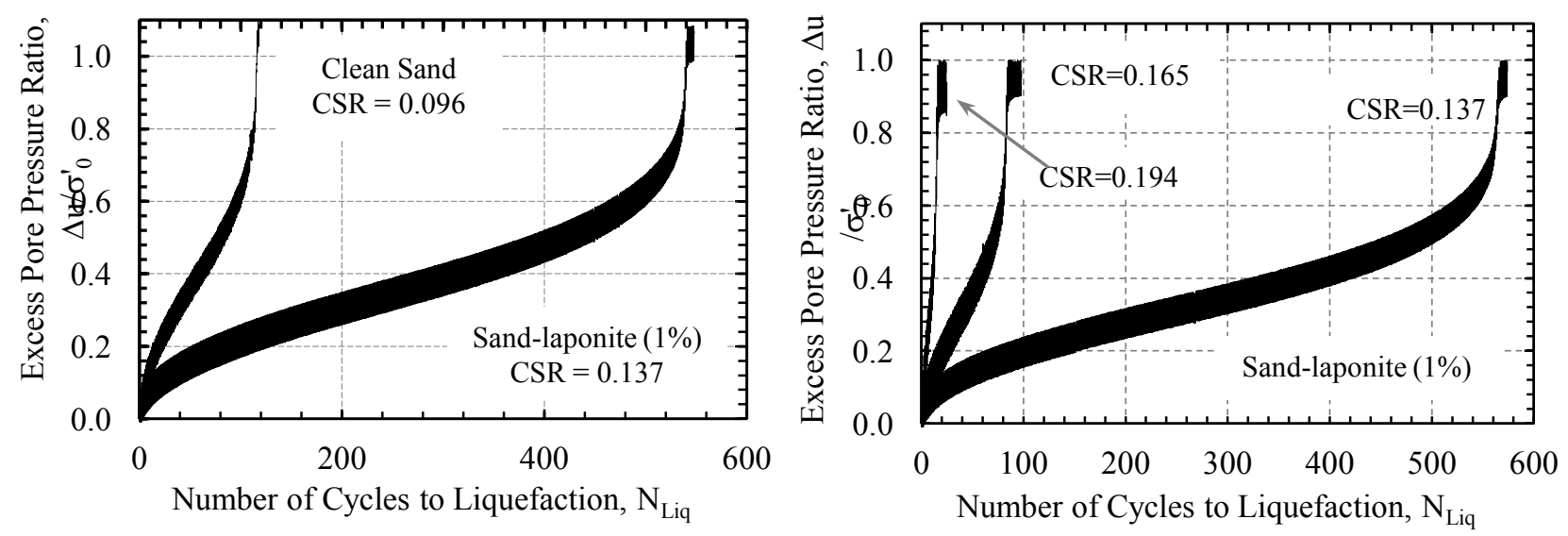

Figure 6. Excess pore pressure during cyclic loading: (a) clean sand versus sand-laponite specimens; (b) sand-laponite specimens sheared at different CSR 

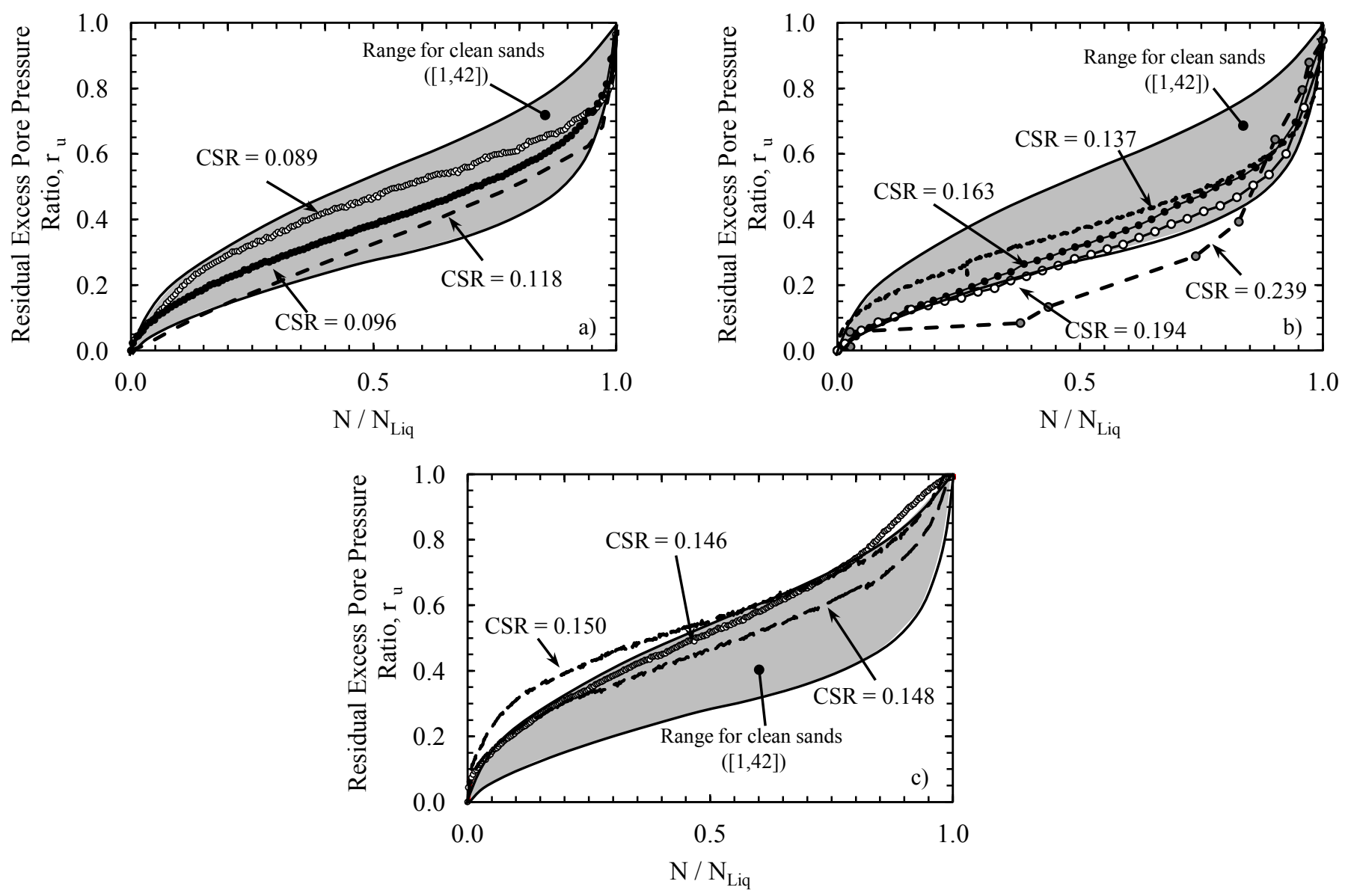

Figure 7. Residual excess pore pressure ratio versus $\mathrm{N} / \mathrm{N}_{\mathrm{Liq}}$ for specimens of (a) clean sand, (b) sand with $1 \%$ laponite, and (c) sand with $3 \%$ laponite 


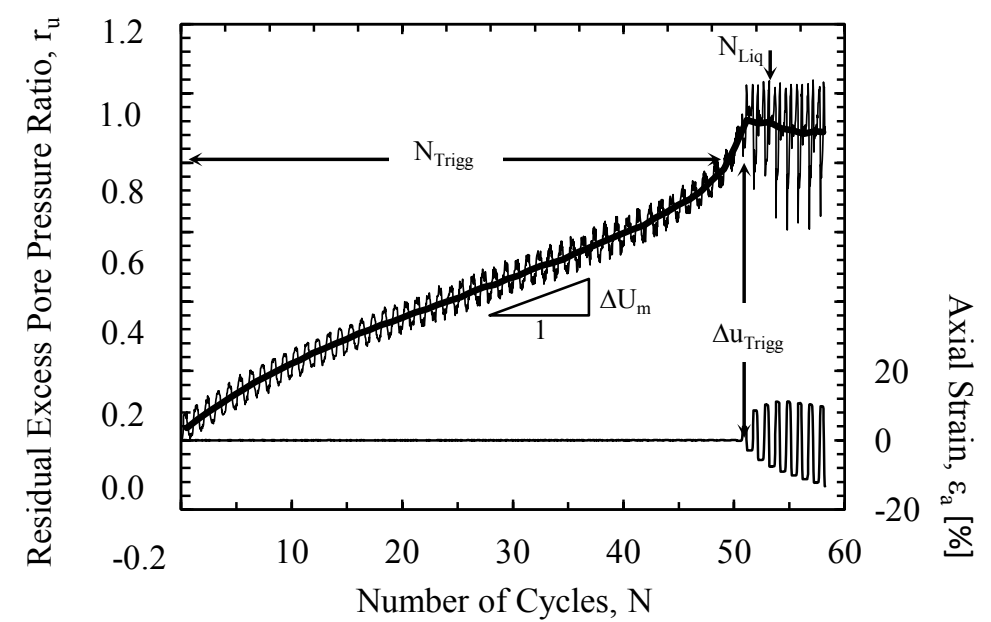

Figure 8. Stages of excess pore pressure generation and axial strain development during undrained cyclic triaxial loading 

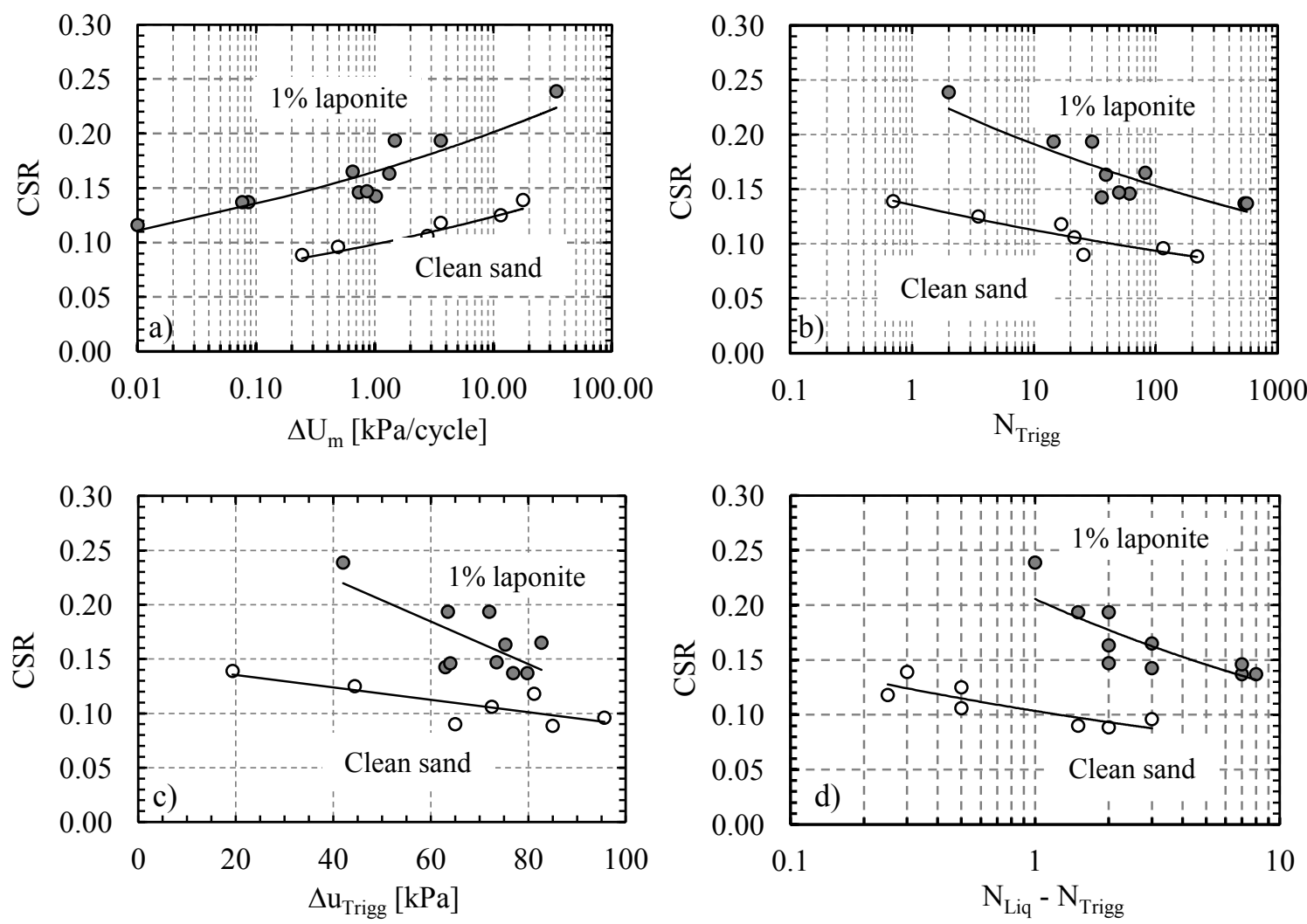

Figure 9. CSR versus (a) $\Delta \mathrm{U}_{\mathrm{m}^{\prime}}$; (b) $\mathrm{N}_{\text {trigg; }}$ (c) $\Delta \mathrm{u}_{\text {Trigg. }}$; and (d) $\mathrm{N}_{\text {Liq }}-\mathrm{N}_{\text {Trigg }}$ 

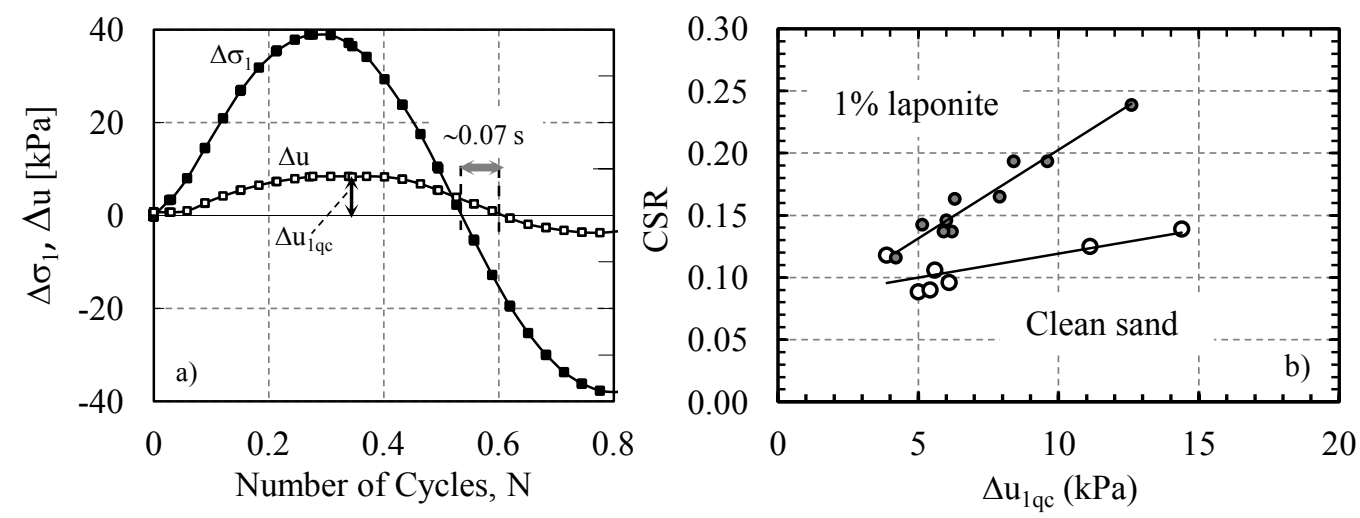

Figure 10. (a) Example of variation of deviator stress and pore pressure during first half cycle of cyclic shear phase, and (b) CSR versus excess pore pressure generated in the first quarter of the first loading cycle $\left(\Delta \mathrm{u}_{1 \mathrm{qc}}\right)$ 


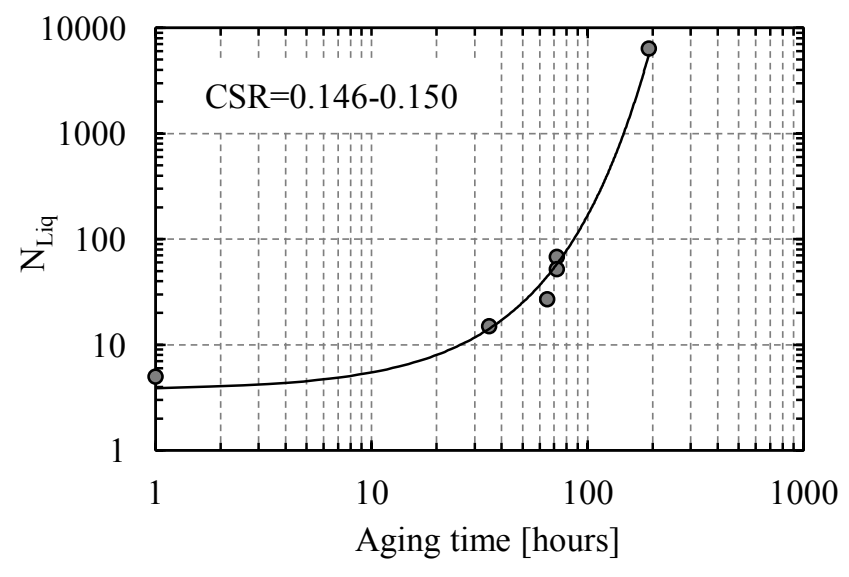

Figure 11. Increase in cycles to liquefaction with post-consolidation aging time of sand-laponite (1\%) specimens (Tests L-5, L-6, L-7, L-13, L-14, L-15) 


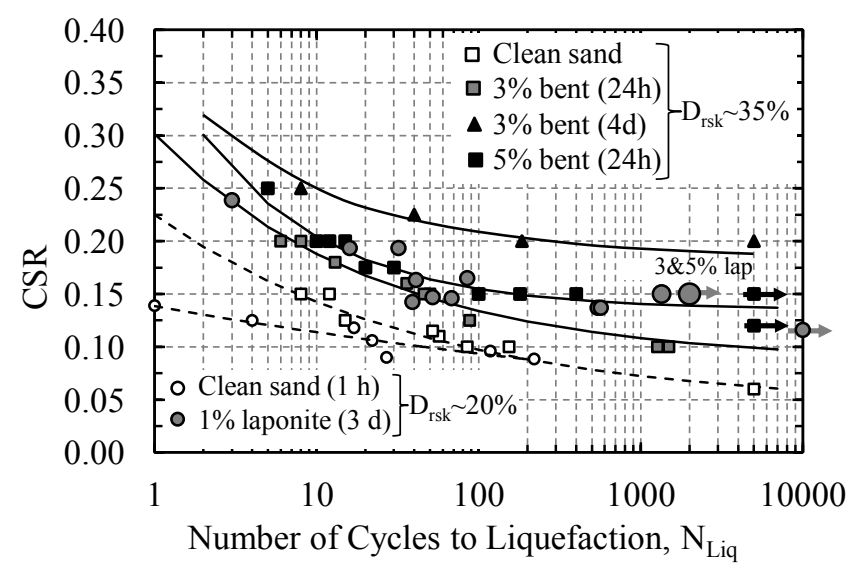

Figure 12. CSR vs Number of cycles to liquefaction; comparison between clean sand, sand-laponite and sand-bentonite (bentonite data from [22]) 

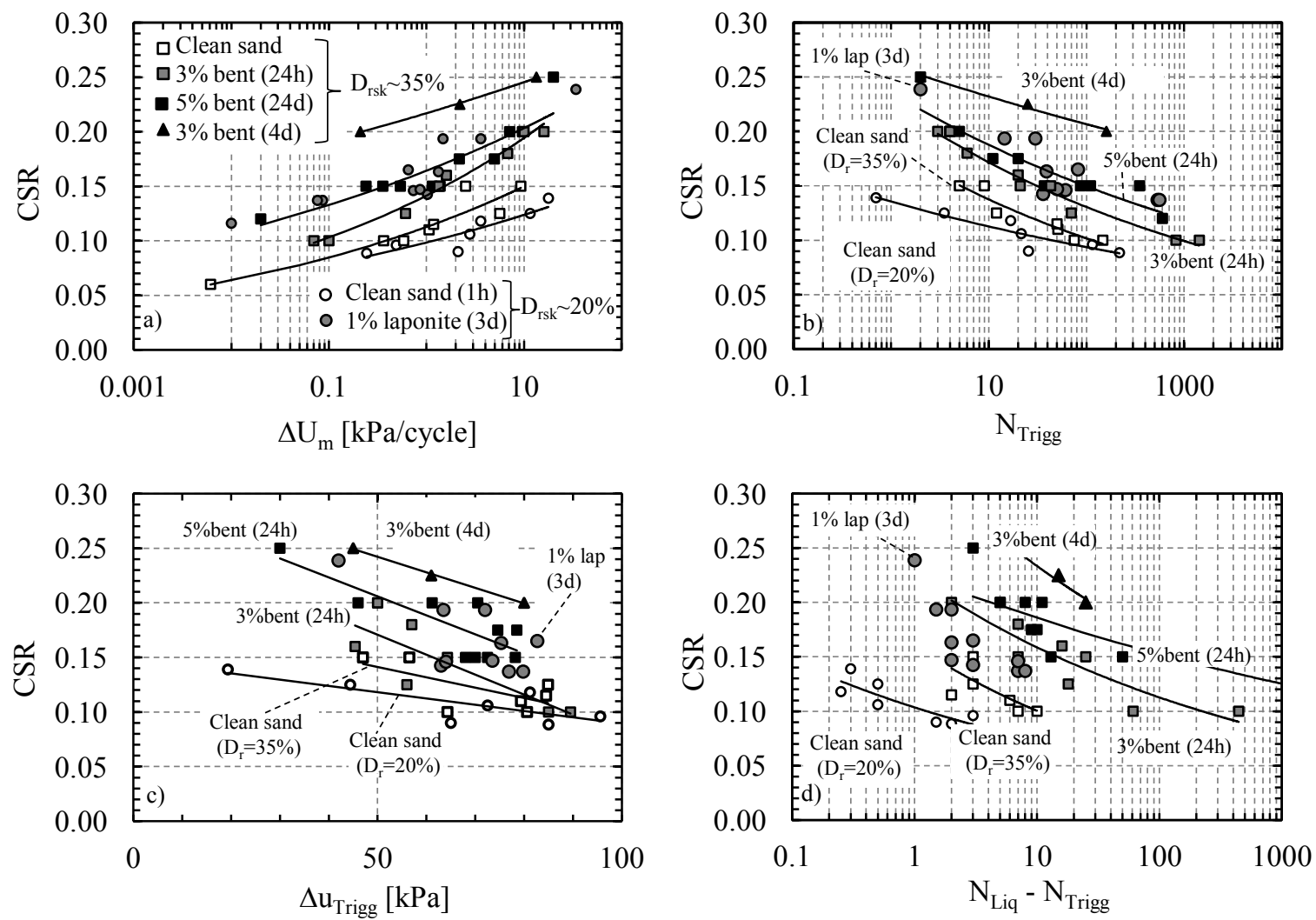

Figure 13. Comparison between clean sand, sand-laponite and sand-bentonite results: $\operatorname{CSR}$ versus (a) $\Delta \mathrm{U}_{\mathrm{m}}$; (b) $\mathrm{N}_{\text {trigg; }}$; (c) $\Delta \mathrm{u}_{\text {Trigg, }}$ (d) $\mathrm{N}_{\text {Liq }}-\mathrm{N}_{\text {Trigg. }}$ (bentonite data from [23]) 


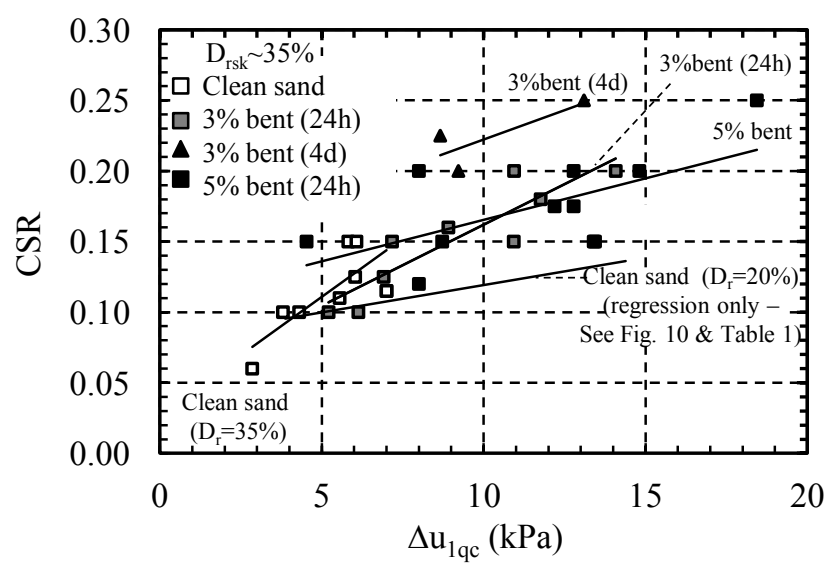

Figure 14. CSR versus excess pore pressure generated in the first quarter of the first loading cycle: comparison between clean sand and sand-bentonite specimens 